\title{
Stimulated Reservoir Volume Characterization and Optimum Lateral Well Spacing Study of Two-Well Pad: Midland Basin Case Study
}

\author{
Jaeyoung Park $\mathbb{D i D}^{1}$ and Candra Janova $\mathbb{D}^{2}$ \\ ${ }^{1}$ Petroleum Engineering, Texas A\&M University, 3116 TAMU, College Station, TX 77843, USA \\ ${ }^{2}$ Parsley Energy, Austin, TX 78701, USA \\ Correspondence should be addressed to Jaeyoung Park; pjy7026@tamu.edu
}

Received 14 September 2020; Revised 7 October 2020; Accepted 20 October 2020; Published 17 November 2020

Academic Editor: Kyungbook Lee

Copyright (c) 2020 Jaeyoung Park and Candra Janova. This is an open access article distributed under the Creative Commons Attribution License, which permits unrestricted use, distribution, and reproduction in any medium, provided the original work is properly cited.

\begin{abstract}
This paper introduces a flow simulation-based reservoir modeling study of a two-well pad with long production history and identical completion parameters in the Midland Basin. The study includes building geologic model, history matching, well performance prediction, and finding optimum lateral well spacing in terms of oil volume and economic metrics. The reservoir model was constructed based on a geologic model, integrating well logs, and core data near the target area. Next, a sensitivity analysis was performed on the reservoir simulation model to better understand influential parameters on simulation results. The following history matching was conducted with the satisfactory quality, less than $10 \%$ of global error, and after the model calibration ranges of history matching parameters have substantially reduced. The population-based history matching algorithm provides the ensemble of the history-matched model, and the top 50 history-matched models were selected to predict the range of Estimate Ultimate Recovery (EUR), showing that P50 of oil EUR is within the acceptable range of the deterministic EUR estimates. With the best history-matched model, we investigated lateral well spacing sensitivity of the pad in terms of the maximum recovery volume and economic benefit. The results show that, given the current completion design, the well spacing tighter than the current practice in the area is less effective regarding the oil volume recovery. However, economic metrics suggest that the additional monetary value can be realized with $150 \%$ of current development assumption. The presented workflow provides a systematic approach to find the optimum lateral well spacing in terms of volume and economic metrics per one section given economic assumptions, and the workflow can be readily repeated to evaluate spacing optimization in other acreage.
\end{abstract}

\section{Introduction}

The Permian Basin is one of the largest hydrocarbonproducing basins in the United States and the World. In 2017, the basin accounted for $20 \%$ of the total crude oil production and about $9 \%$ of the total dry natural gas production in the United States [1]. The estimation by EIA [2] suggests that the remaining proven reserves in the Permian Basin to exceed 5 billion barrels of oil and 19.1 trillion cubic feet of natural gas. Our study area, the Midland Basin, is a part of the Permian Basin along with the Delaware Basin and the Central Basin Platform. USGS estimated undiscov- ered, continuous, hydrocarbon resources of the Wolfcamp formation in the Midland Basin alone to be approximately 20 billion barrels of oil and 16 trillion cubic feet of natural gas [3]. As the interest in development of the area grows, more than 3,000 horizontal wells have been drilled and hydraulically fractured in the Midland Basin Wolfcamp formation [3]. Due to a large number of newly drilled wells and overwhelming volume of data, data-driven, empirical, and simplified physics-based methods are frequently utilized for analyzing well performance and evaluating the field development plan. Such methods include decline curve analysis and rate transient analysis that are timely effective 
and cost less manpower. However, to address challenging questions in the unconventional reservoir, aforementioned methods might not be sufficient. For example, to find the optimum well spacing is a fundamental question to effectively and economically develop the unconventional field. However, the well spacing problem is associated with stimulated multiwell, interference, and communication between them where the physics should not be missed to accurately address the problem. Therefore, the physic-based reservoir modeling study is essential in order to better understand and capture complex dynamics in the unconventional reservoir and characterize hydraulic fractures [4].

There have been studies to investigate the optimum well spacing in the development of tight shale reservoirs in the Permian Basin, utilizing the physic-based reservoir simulation work. Cullick and Carrillo [5] studied well spacing for vertical wells fractured from Spraberry to Atoka to develop stack tight oil pay in the Midland Basin. Pettegrew and Qiu [6] utilized data analytics and reservoir simulations to determine the relationship between EUR and well spacing for the Wolfcamp formation in the Delaware Basin. Liang and Du [7] investigated a wide range of fracture design and well spacing scenarios using reservoir simulations and validate their regression on EUR with field test results from the Permian Basin. Zhu and Forrest [8] conducted a simulation-based cluster and well spacing optimization study for the Lower Spraberry shale in the Midland Basin, emphasizing the importance of accurately determining hydraulic fracture half-length. Ajisafe and Solovyeva [9] investigated the impact of well spacing ( $660 \mathrm{ft}$ and 1,320 ft) on the production performance of parent and child wells in the Permian Basin by looking at the recovery volume. Pankaj [10] illustrated single or multiwell pad optimization workflow which includes hydraulic fracture calibration and simulations of wide range of sensitivity cases to draw insights in well spacing and completion design for the Wolfcamp formation in the Permian Basin. Bansal and Han [11] performed the simulation-based reservoir characterization to understand optimal well spacing in the Wolfcamp formation, Delaware Basin. They calibrated a multiwell reservoir model and investigated oil recovery degradation with different configuration of wells.

The objective of this study is to perform the flow simulation-based reservoir modeling of a two-well pad asset with long production history and identical completion in the Midland Basin. Specifically, the objective includes the following goals: (1) understand fracture properties and reservoir depletion of the asset, (2) predict future production of each well, and (3) find the optimum well spacing in the area based on the recovery volume and economic metrics by using history matching results. The area is selected because the operator has a good geologic control from well log and core data and retains sufficient production history data, more than two years, to be analyzed. The paper first introduces history data of two-well pad and detailed reservoir model calibration methodology and results. Given the history matching results, the production forecast and lateral spacing sensitivity study are presented. This paper provides a workflow for a systematic approach from model calibration to EUR estimation and quantifying the optimum lateral spacing in terms of volume and economic metrics per one section. Compared to previous studies, the current study specifically targets a two-well pad in the Wolfcamp formation in the Midland Basin, integrating broad ranges of data including well responses and geologic properties from well logs. This study suggests that the optimum well spacing not only for the recovery volume but also for economic metrics, based on reservoir simulation results and real economic parameters, which is practical and helpful for the unconventional field development and decision-making.

\section{Methodology}

A county-scale geologic model was constructed using well log and core data around the target area. The reservoir model was sliced in an area slightly larger than one section as a part of the geologic model, and its properties were upscaled within the CMG platform. In order to calibrate the reservoir model by history matching, we first defined history matching parameters to calibrate and their uncertainty ranges, mainly associated with hydraulic fractures, permeability enhanced zone, and reservoir properties. Before the history matching, we performed a sensitivity analysis to better understand "heavy hitters," influential parameters to simulation results, in this particular history matching problem. The following model calibration that minimizes errors between simulation results and history data using a population-based algorithm was conducted targeting less than $10 \%$ of the global error, substantially reducing ranges of history matching parameters. The top 50 models capable of reproducing history data with satisfactory quality, less than $10 \%$ global error, were selected for the production forecasting of the wells by simulating oil and gas production with constant bottom-hole pressure (BHP) constraint for the total of 35 years. Lastly, the lateral well spacing sensitivity was investigated with the best history-matched model to find the maximum oil volume recovery and profitability by varying lateral spacing of the history-matched two-well pad.

\section{History Matching of Two-Well Pad}

3.1. History Data. The wells in the pad have history data more than two years. The provided history data includes water cut, gas oil ratio (GOR), fluid production rates, and bottom-hole pressure (BHP) as illustrated in Figure 1. Since measured BHP from the downhole is originally unavailable, we back-calculated the BHP from the production data, wellhead pressure, PVT data, and wellbore properties using the Hagedorn and Brown correlation $[12,13]$. In general, the wells show similar production trend in the fluid production and BHP. Figures 1(c) and 1(d) show water cut for both wells that stay relatively flat within ranges of 0.6-0.7 for the entire history. However, GOR increases over time, implying that as the reservoir depletes below the bubble point pressure, more gas is liberated from the reservoir. The bottom of the first two left columns of the figure shows water, gas, and oil rates and calculated BHP. 


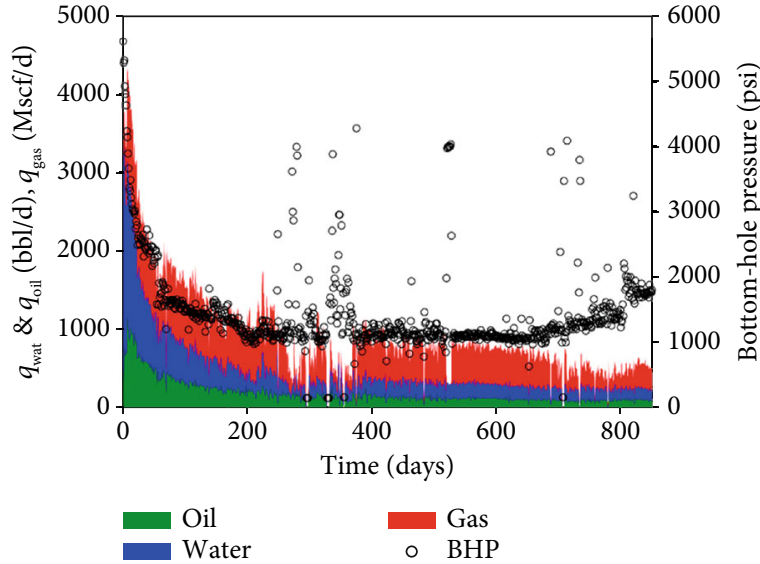

(a)

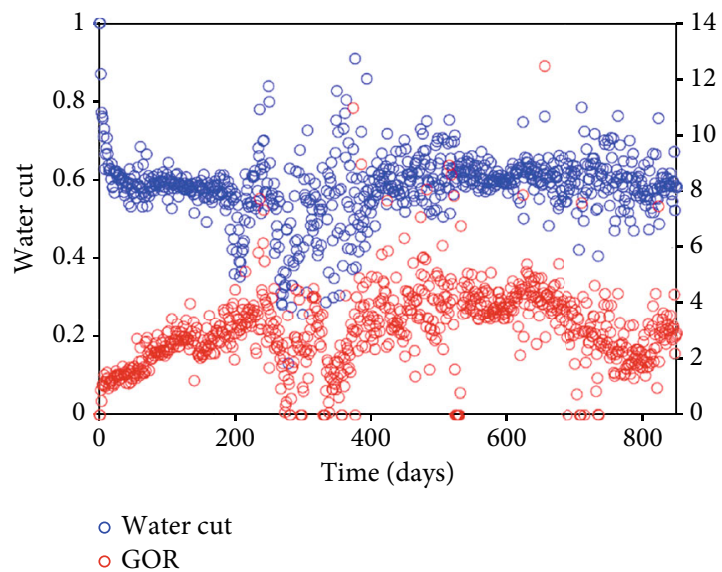

(c)

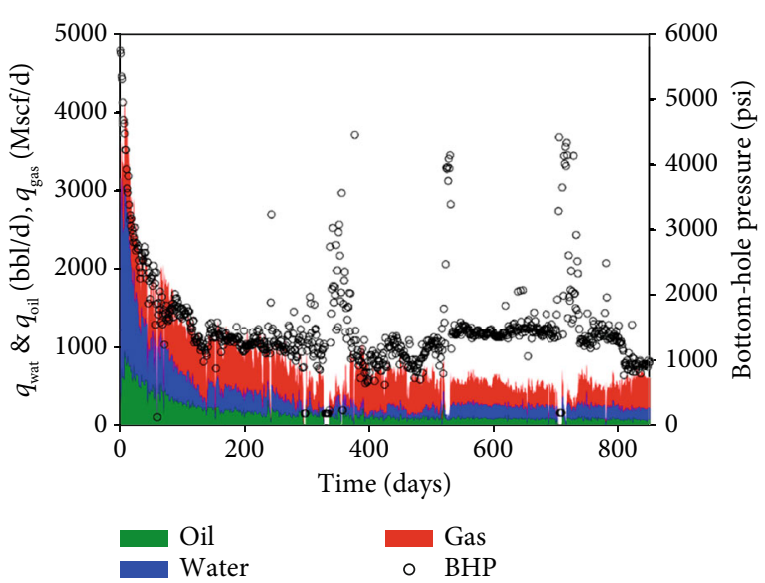

(b)

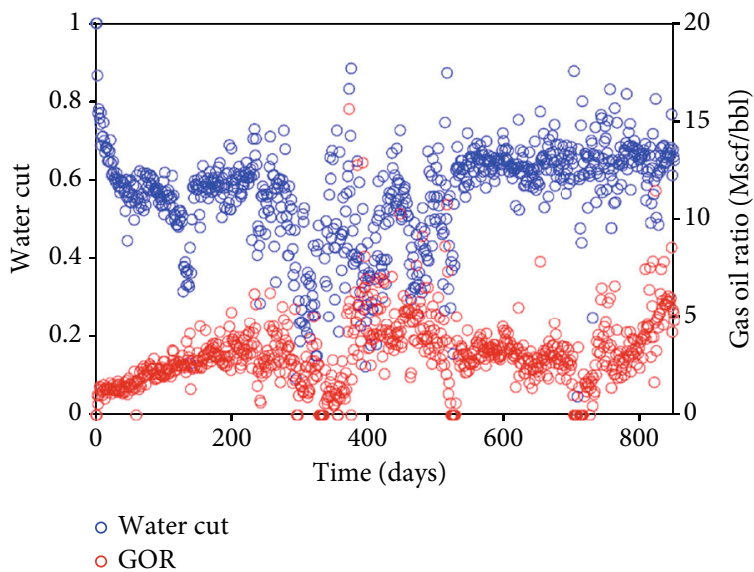

(d)

Figure 1: History data for well A and well B: (a) production rates and bottom-hole pressure for well A, (b) production rates and bottom-hole pressure for well B, (c) water cut and gas oil ratio for well A, and (d) water cut and gas oil ratio for well B.

The comparison in production rates and BHP between two wells shows that well $\mathrm{A}$ has been producing more fluids than well B (Figure 2). This is possibly resulted from depletion effects from a neighboring well in the adjacent section causing well B performing slightly lower. The detailed information of the wells including the highest initial production in oil and gas, stimulated lateral length (SLL), injected proppant and fluid, and the number of stages is summarized in Table 1. The wells have been put on production (POP) concurrently with same targeting, stimulated lateral length, and completion design.

3.2. Reservoir Simulation Domain Description. The reservoir simulation work in this study was performed in the CMG platform using CMG IMEX, a black-oil simulator. The key features of CMG IMEX for unconventional reservoirs include local grid refinement (LGR), modeling biwing hydraulic fractures and complex hydraulic fracture network, and comprehensive horizontal well management [14]. A number of existing body of well spacing studies in hydraulically fractured unconventional reservoirs $[5,6,15]$ have utilized CMG IMEX. The current study utilizes LGR and biwing hydraulic fractures to represent the part of the reservoir stimulation.

Figure 3 illustrates the reservoir simulation model used for history matching. The reservoir is initially undersaturated. The initial reservoir pressure ranges 5,100-5,400 psi depending on true vertical depth (TVD), and the bubble pressure is $3,500 \mathrm{psi}$. The size of the $3 \mathrm{D}$ reservoir simulation domain is $2,200 \mathrm{ft}$ in the $i$-direction, $7,250 \mathrm{ft}$ in the $j$-direction, and $820 \mathrm{ft}$ in the $k$-direction which consists of approximately 146,000 grid cells. Each well has 30 stages. However, we only have 35 main hydraulic fractures in the model to represent 30 stages primarily due to the size of the grid cell created in the model. Instead, we introduced a permeability enhanced zone to represent a part of the reservoir stimulation.

As previous field observations [16-18] and numerical studies [19-21] showed, multistage hydraulic fractures might not propagate uniformly, yet planar and biwing fractures are assumed in the model. The hydraulic fractures described in the reservoir model implies hydraulically induced and also propped fractures which indeed contribute fluid production of stimulated wells. Local grid refinement (LGR) was utilized 

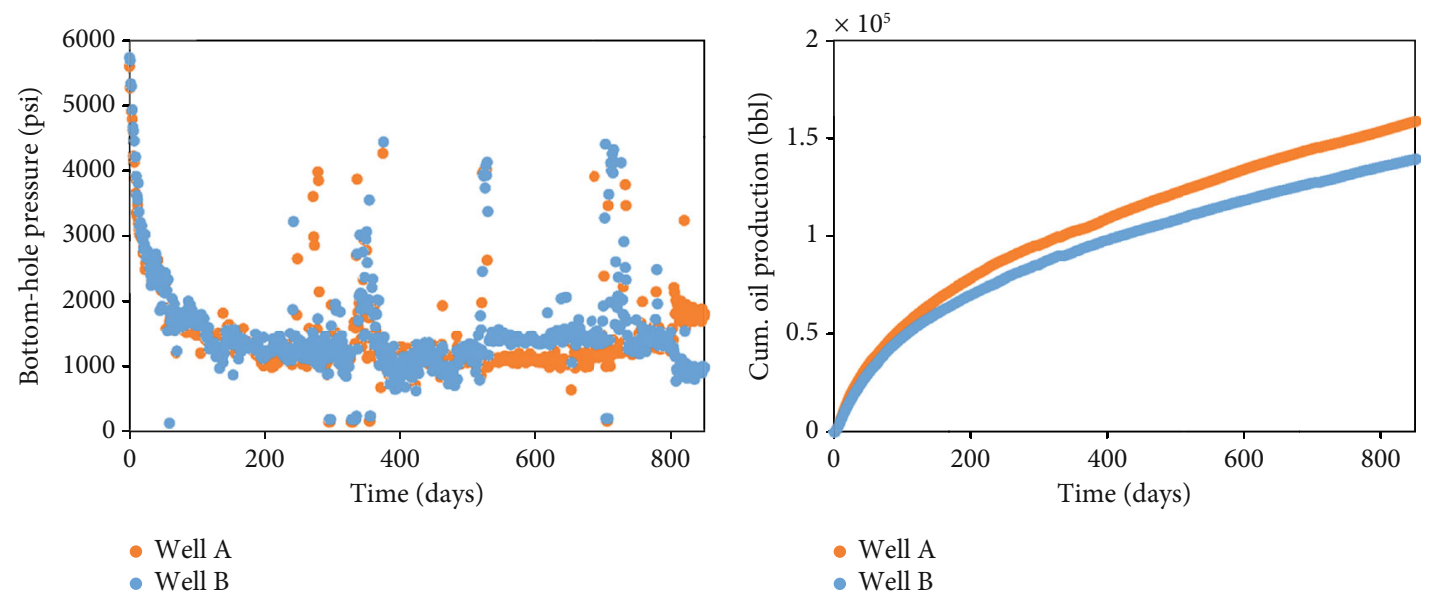

(a)

(b)

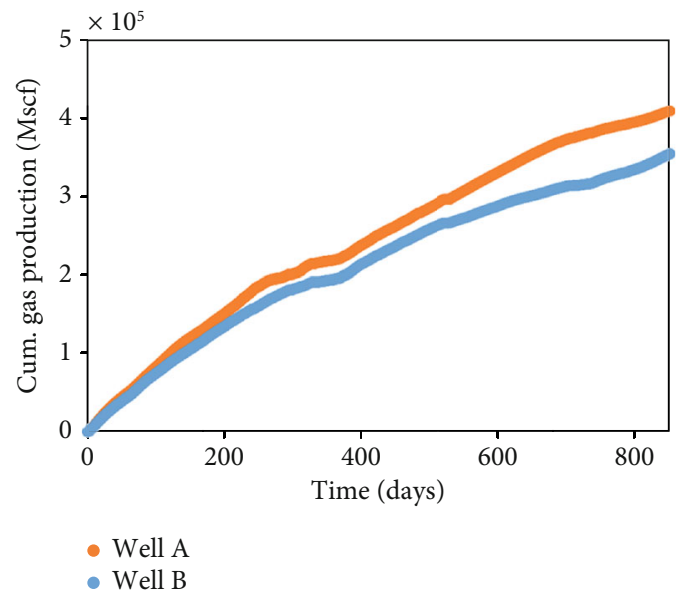

(c)

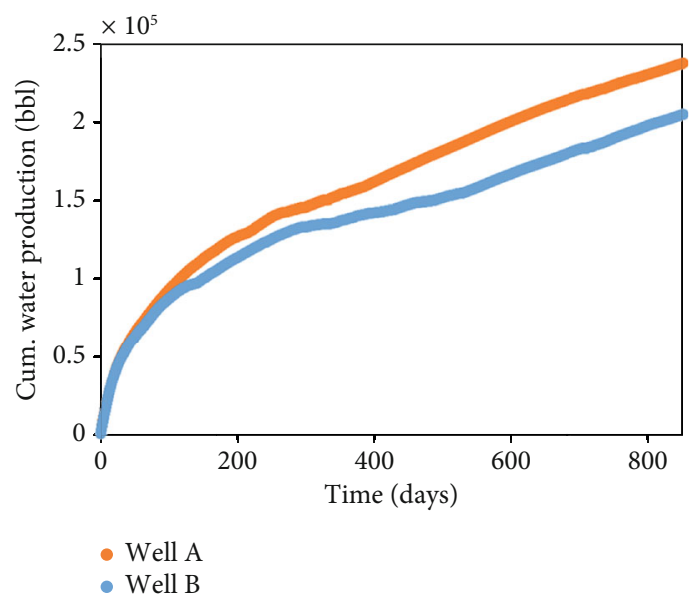

(d)

FIgURE 2: Production data comparison: (a) bottom-hole pressure, (b) cumulative oil production, (c) cumulative gas production, and (d) cumulative water production.

TABLE 1: The summary of production and completion information on well A and well B.

\begin{tabular}{lccccccc}
\hline Well & POP & IP30 [BOPD] & IP30 [MCFD] & SLL [ft] & Proppant [lb/ft] & Stages & Fluid [bbl/ft] \\
\hline Well A & $01 / 26 / 16$ & 799 & 1,128 & 5,089 & 1,640 & 30 & 40.8 \\
Well B & $01 / 25 / 16$ & 673 & 1,044 & 5,086 & 1,746 & 30 & 43.3 \\
\hline
\end{tabular}

to describe the main hydraulic fractures [22], and we assigned high permeability around fractures to describe permeability enhanced zone due to the reservoir stimulation [11, 23]. The detailed configuration of the model around the fractures is presented in Figure 3. The red part represents the main fractures with LGR, the yellow part is permeability enhanced zone, and the blue part shows matrix where there is no permeability change due to the stimulation. Therefore, there are three different zones that contribute to fluid production in the reservoir simulation model.

Continuing with the reservoir model description, Figure 4 shows permeability in the $i$-direction, porosity, and water saturation in the $j-k$ section. The model covers from the upper Wolfcamp (upper WC) all the way down to the lower Wolfcamp (lower WC), and our target is the middle Wolfcamp (middle WC). It should be noted that the model honors heterogeneity and variations in properties vertically as well as horizontally.

Figure 5 illustrates the variation in properties as function of TVD. Middle WC shows relatively high permeability especially in the upper part of the middle WC. When it comes to saturation, upper WC shows a high oil saturation, whereas the lower WC is more water-saturated. Well A and well B landed mainly in the lower middle WC highlighted in the 


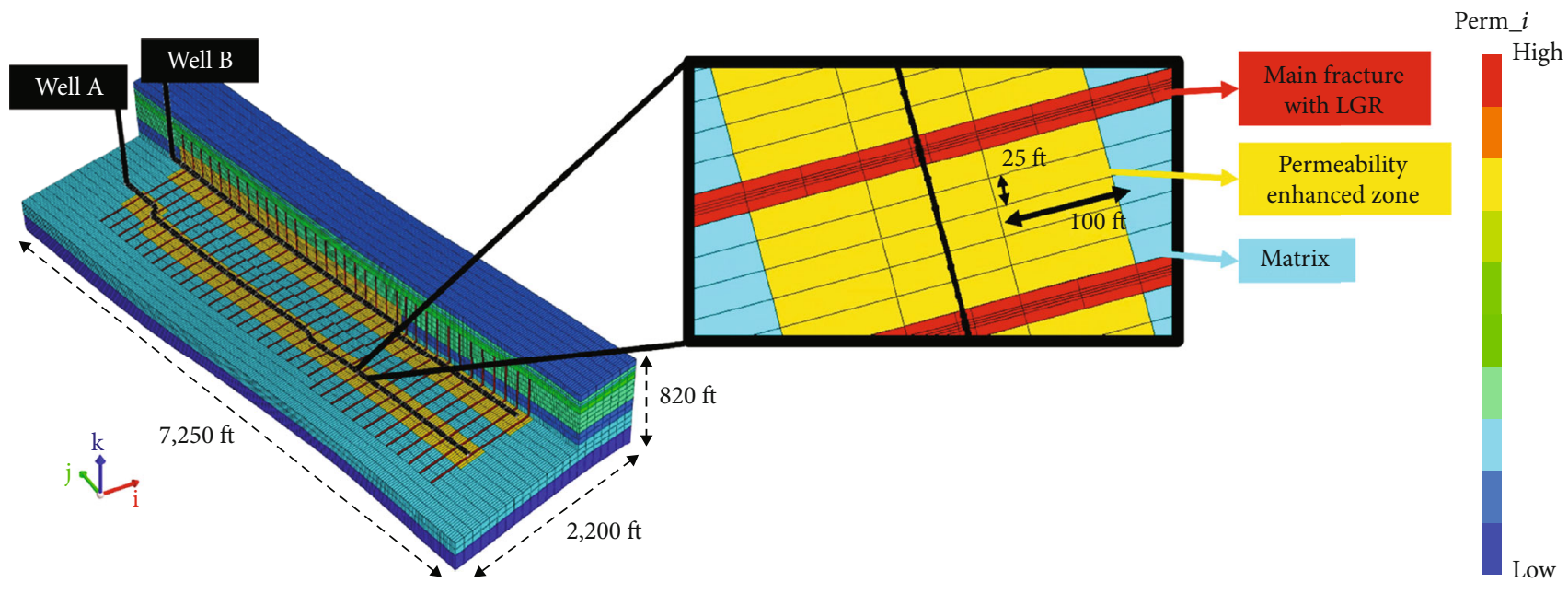

FIgURE 3: Reservoir simulation model for history matching.

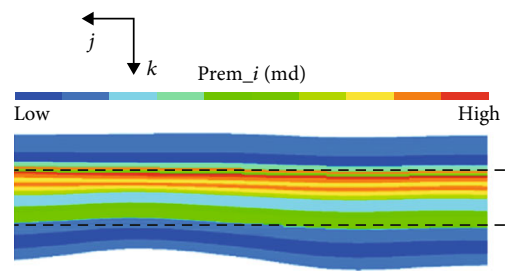

(a)

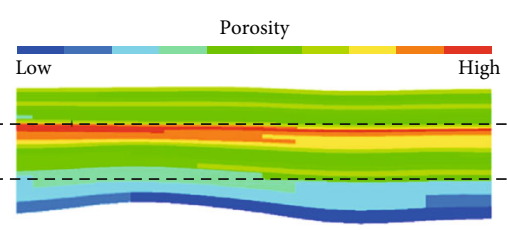

(b)

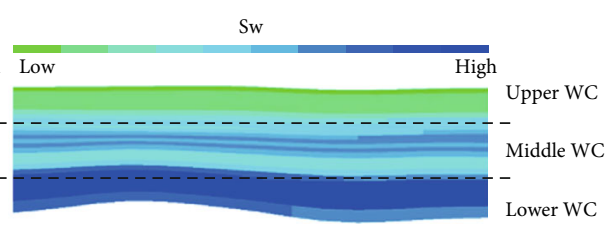

(c)

FIGURE 4: Reservoir model $j-k$ cross-section: (a) permeability, (b) porosity, and (c) water saturation.

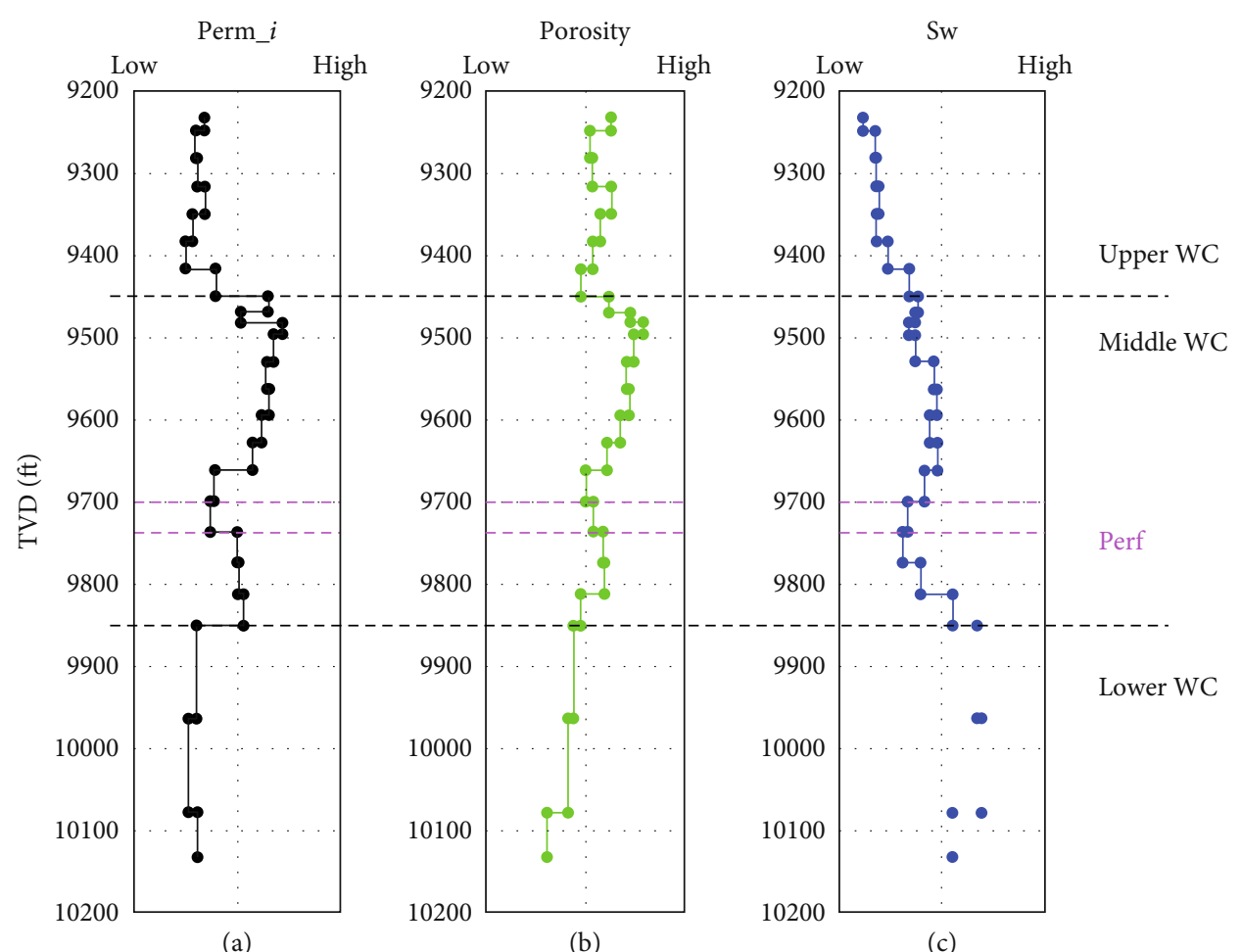

Figure 5: Property variation along depth: (a) permeability in the $i$-direction, (b) porosity, and (c) water saturation. 
TABLE 2: The average values for properties in different formations.

\begin{tabular}{lccc}
\hline \multirow{2}{*}{ Formation } & $\begin{array}{c}\text { Permeability } i(1 \mathrm{e}-3 \mathrm{md}) \\
\text { Avg. }\end{array}$ & $\begin{array}{c}\text { Porosity } \\
\text { Avg. }\end{array}$ & $\begin{array}{c}\text { Water saturation } \\
\text { Avg. }\end{array}$ \\
\hline Upper WC & 2.2 & 0.05 & 0.21 \\
Upper middle WC & 38.5 & 0.06 & 0.43 \\
Lower middle WC & 8.2 & 0.05 & 0.40 \\
Lower WC & 1.5 & 0.04 & 0.63 \\
\hline
\end{tabular}

TABLE 3: History matching parameters. The superscript ${ }^{(1)}$ indicates fractures for well A and well B that can have different values, and ${ }^{(2)}$ indicates each permeability enhanced zone that can have different values.

\begin{tabular}{|c|c|c|c|c|}
\hline Category & History matching parameters & Low & Base & High \\
\hline \multirow{6}{*}{ Hydraulic fractures } & Height_up (\# of grid) & 2 & 5 & 8 \\
\hline & Height_down (\# of grid) & 0 & 0 & 2 \\
\hline & Half length $(\mathrm{ft})$ & 100 & 200 & 300 \\
\hline & Permeability $^{(1)}(\mathrm{md})$ & 1 & 10 & 50 \\
\hline & Compaction table $\mathrm{e}^{(1)}$ & 1 & 5 & 11 \\
\hline & Water saturation $^{(1)}$ & 0.6 & 0.7 & 0.8 \\
\hline \multirow{2}{*}{ Permeability enhanced zone } & Permeability multiplier ${ }^{(2)}$ & $10^{0}$ & $10^{1}$ & $10^{2.5}$ \\
\hline & Compaction table ${ }^{(2)}$ & 1 & 5 & 11 \\
\hline \multirow{2}{*}{ Reservoir properties } & KvKh (permeability anisotropy) & 0.05 & 0.1 & 0.2 \\
\hline & Rock compressibility (1/psi) & $1 e-6$ & $2 \mathrm{e}-6$ & $3 e-6$ \\
\hline
\end{tabular}

magenta dashed line in Figure 5. The minimum, maximum, and the average values of permeability, porosity, and water saturation in each formation are summarized in Table 2.

3.3. History Matching Methodology and Parameters. The model calibration process involves adjusting history matching parameters such that the reservoir simulation results can closely reproduce field measurements. By minimizing errors between responses from the reservoir simulation and production history data, uncertainties associated with the parameters of the model are expected to reduce, and we build more confidence in our calibrated models. History matching in this study was performed using the CMG CMOST module [24] with its intrinsic evolutionary algorithm for optimization, Design Exploration Controlled Evolution. CMG IMEX was utilized as a forward simulator, and the simulation is constrained by the oil rate. This is because the oil production rate is the most accurate among the measurements, and we do not want the oil production to be compromised when it comes to economic metric calculation. The global objective function to minimize is a weighted sum of errors in cumulative gas and water productions and BHP of the wells. The total number of simulation runs is set to 1,000 , and the computation time for one simulation takes less than 10 minutes with 4 CPUs per job.

Table 3 summarizes the parameters to calibrate during the history matching process. Other parameters that are not listed but critical in the multiphase reservoir simulations such as relative permeability and PVT data are referred from previous internal studies and lab measurements. The history matching parameters can be categorized into three groups: hydraulic fracture related parameters, permeability enhanced zone related parameters, and reservoir properties. The permeability enhanced zone is subdivided into five regions based on variation in the wellbore geometry (Figure 6(a)).

The fracture-related parameters are mainly associated with fracture geometry and its properties such as permeability, water saturation, and compaction table. We adjust the initial water saturation of the hydraulic fracture to demonstrate high water production in early time due to stimulated water. A compaction table is a way to describe changes in permeability and porosity. It is frequently used in unconventional reservoir simulations because it allows us to emulate degradation and reduction in fracture permeability and porosity due to reservoir depletion, simply with the function of pressure. Figures 6(b) and 6(c) show a series of permeability and porosity multiplier (CTYPE). The porosity multiplier table is generated using

$$
\text { poro }_{\mathrm{MLT}}=1+c_{\text {por }}\left(p-p_{\text {ref }}\right)
$$

where $c_{\text {por }}$ is the rock compressibility, $p_{\text {ref }}$ is the reference pressure, and $p$ is the pressure which is a variable. The permeability multipliers are determined by the modified equation from Espinoza [25].

$$
\operatorname{perm}_{\mathrm{MLT}}=\operatorname{poro}_{\mathrm{MLT}}^{m} \times\left(\frac{1 /\left(\text { poro }_{\text {ini }}-1\right)}{1 /\left(\text { poro }_{\text {ini }}\right)-\text { poro }_{\mathrm{MLT}}}\right)^{m},
$$

where poro $_{\text {ini }}$ is the initial porosity, and $m$ is an adjustable parameter that depends on the rock type. The multiplier 


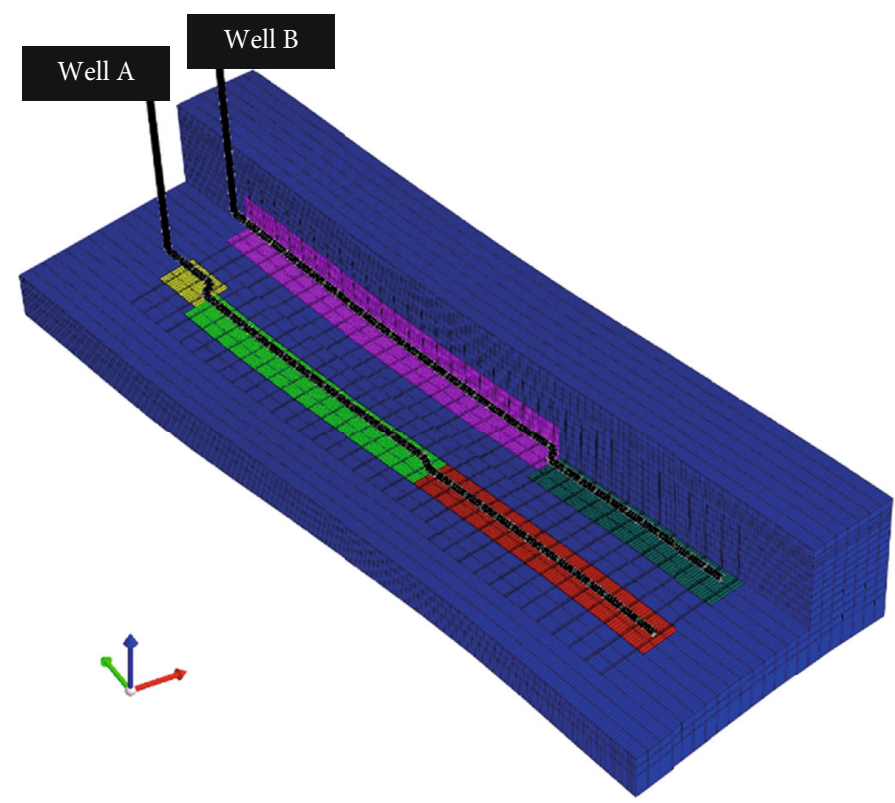

(a)

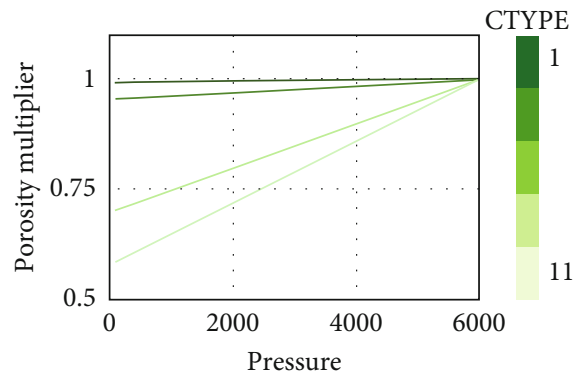

(b)

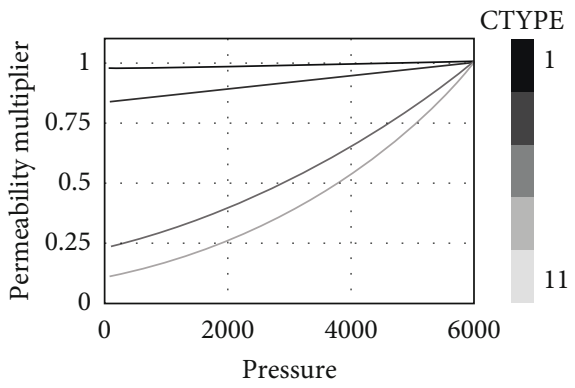

(c)

FIGURE 6: The porosity and permeability multiplier curve as function of pressure (left) and five permeability enhanced zones based on variation in wellbore geometry (right).

tables are predefined using equations (1) and (2). During the history matching, the predefined tables are assigned to the stimulated reservoir volume to the mimic compaction behavior.

The reservoir stimulation was represented with main hydraulic fractures and permeability enhanced zone in the simulation model, and each permeability enhanced zone can have different multiplier values and compaction table number. A permeability multiplier is assigned to the zones rather than the permeability value itself to preserve heterogeneity in the stimulated area near the wells. Reservoir properties in the history matching parameters include permeability anisotropy in the formation and rock compressibility.

3.4. Sensitivity Analysis and History Matching Results. Prior to history matching, we performed a sensitivity analysis. The purpose of the sensitivity analysis is to find heavy hitters. A heavy hitter is a parameter that is more influential than other parameters to simulation results to identify influential parameters for this history matching problem that potentially helps to understand a driving mechanism of the oil production and efficient history matching, reducing less influential parameters. Each objective function presented in Figure 7, errors in cumulative water and gas production and BHP, is defined as aggregated misfits of each data point of two wells. The error between the simulation result and the history data for a well is defined in equation (3) as

$$
Q_{j}=\frac{\sqrt{\sum_{t=1}^{T(j)}\left(Y_{j, t}^{s}-Y_{j, t}^{m}\right)^{2} / \mathrm{NT}(j)}}{\text { scale }_{j}},
$$

where subscripts $j$ and $t$ indicate well and time index, respectively, $\mathrm{NT}(j)$ is the total number of measured data points, $Y_{j, t}^{s}$ is the simulation result, $Y_{j, t}^{m}$ is the measured results, and scale ${ }_{j}$ is the normalization scale to avoid the scale effect when different data types are integrated [24].

The error in the sensitivity analysis is evaluated varying only one parameter at a time, holding the other parameters constant. The color in Figure 7 indicates the relationship between a parameter and an objective function. For example, the positive relationship between the parameter and the objective function is indicated with a blue bar to the right 


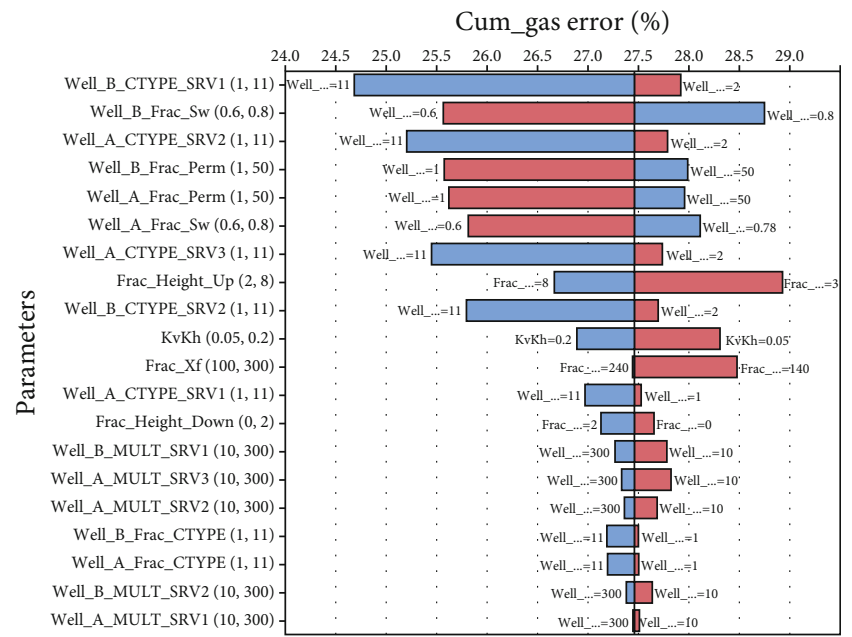

(a)

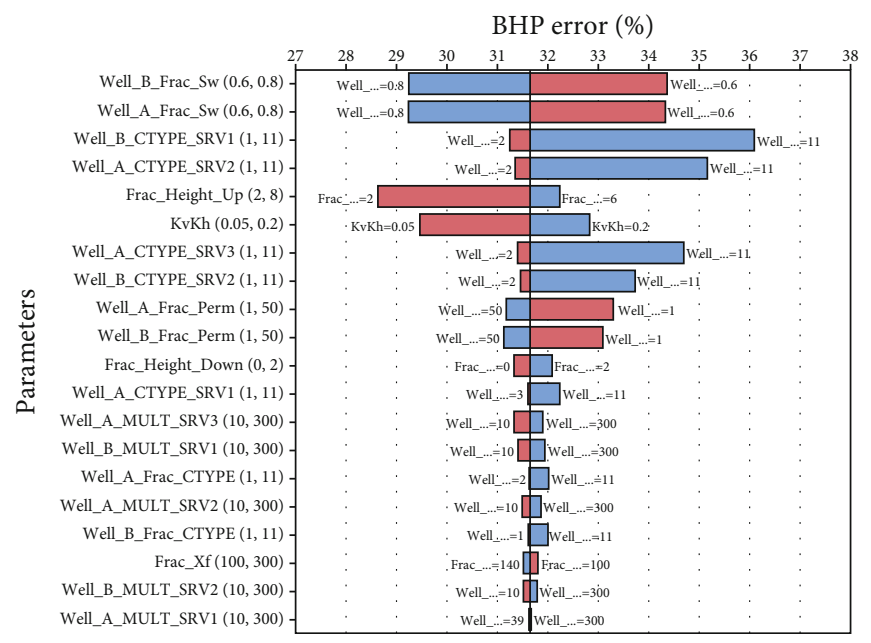

(c)

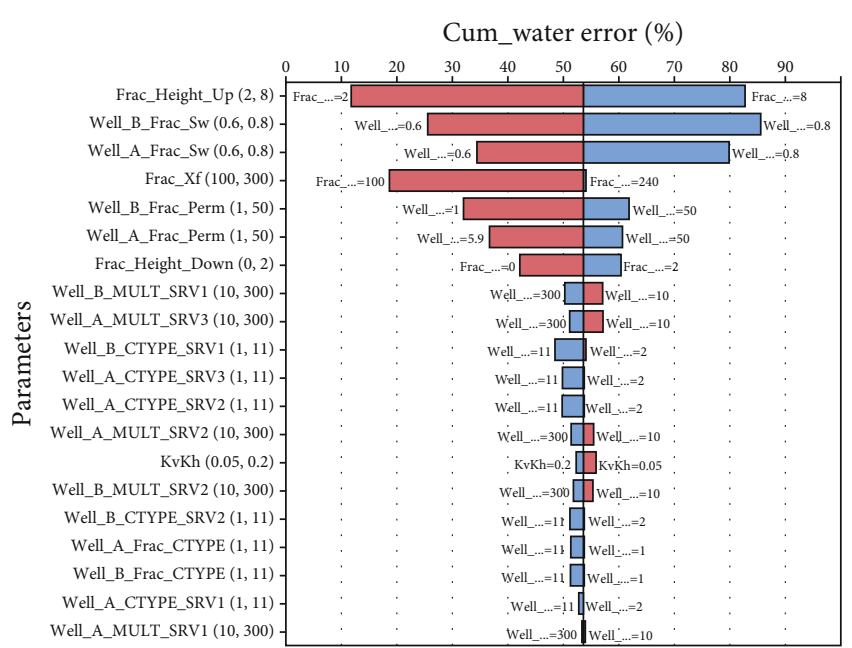

(b)

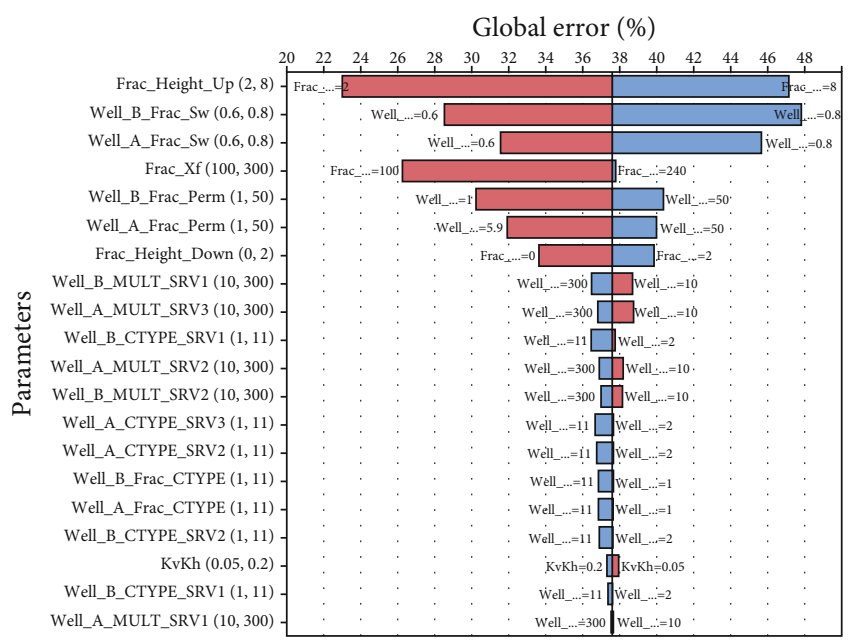

(d)

FIGURE 7: Tornado charts for sensitivity analysis results: (a) cumulative gas production error, (b) cumulative water production error, (c) bottom-hole pressure error, and (d) the global error which is the weighted sum of the three errors.

and the red bar to the left, whereas the negative relationship is represented by the red bar to the right and the blue bar to the left. According to the tornado chart of the global error (Figure $7(\mathrm{~d})$ ), the heavy hitters in this particular history matching problem are the saturations along fractures, fracture permeability, fracture geometry, and permeability multiplier near the wells. This implies that the driving factors for the production in unconventional reservoirs is primarily associated with reservoir stimulation.

Figure 8 shows errors in the $y$-axis and number of simulations in the $x$-axis. We can see that as the history matching proceeds, the algorithm provides better simulation models with less error. The global error in Figure 8(d) is the weighted sum of the errors in cumulative water and gas production and BHP. We took the global error less than $10 \%$ as a satisfactory quality of history matching in the sense that the global error is aggregated errors at each point of different production data types of the wells. We found that all of the top 50 models in terms of the global error are below the
$10 \%$ threshold. The top 50 models in each error are not necessarily identical. This is possibly because objective functions are conflicting with each other. For example, Well_B_ $\mathrm{Frac}_{-} \mathrm{Sw}$, the water saturation of the fracture for well $\mathrm{B}$, has a positive relationship in errors in cumulative gas and water production while the saturation shows a negative relationship with the BHP error. However, the errors at least show a consistent trend. Most of top 50 populations are concentrated in $800^{\text {th }}-1,000^{\text {th }}$ simulation runs. The top 50 models which are the top $5 \%$ of the total population are going to be utilized to assess range of calibrated history matching parameter ranges and production forecasting. The model highlighted with the magenta dot shows the least global error and is referred as the best model hereafter to investigate the reservoir depletion and lateral well spacing sensitivity.

As errors in the objective functions are reduced, the simulation results get closer to the history data. Figure 9 shows the two-year history matching results in time series. Relatively, a good agreement is achieved in cumulative gas and 


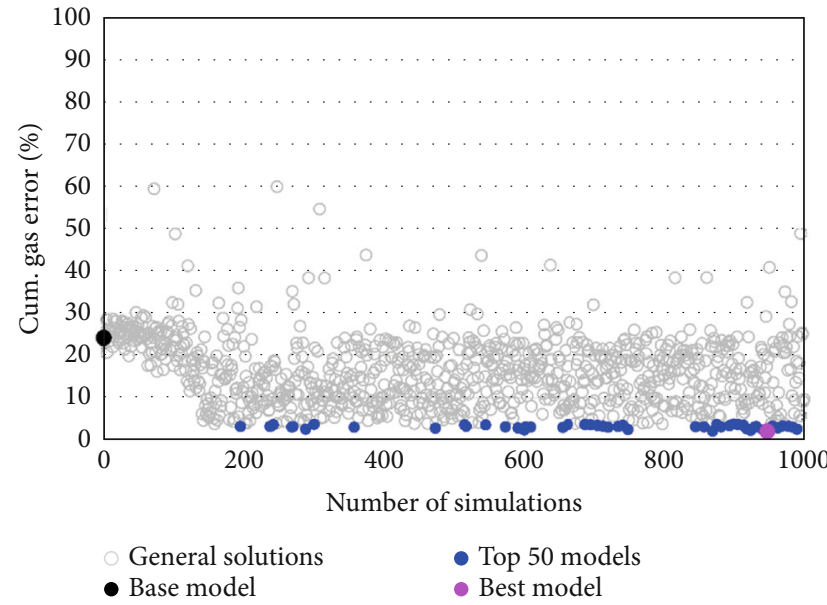

(a)

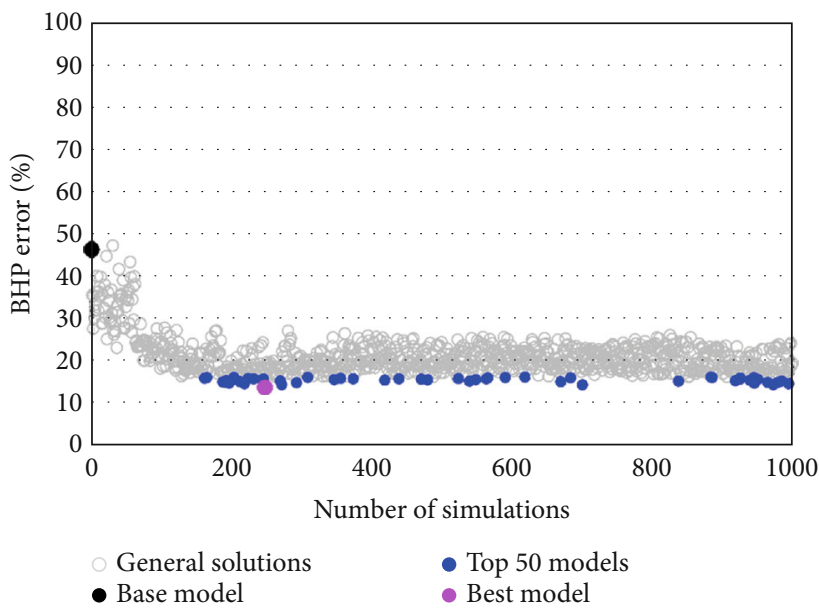

(c)

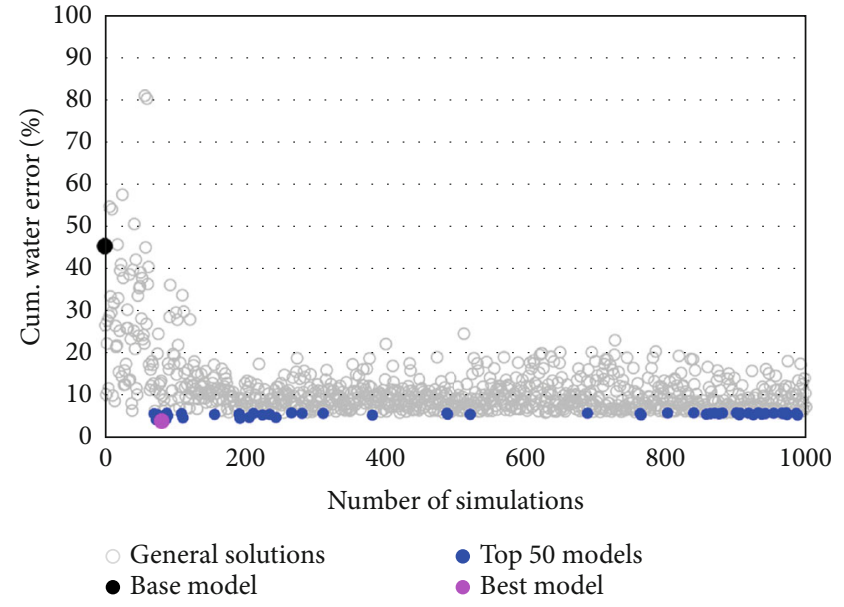

(b)

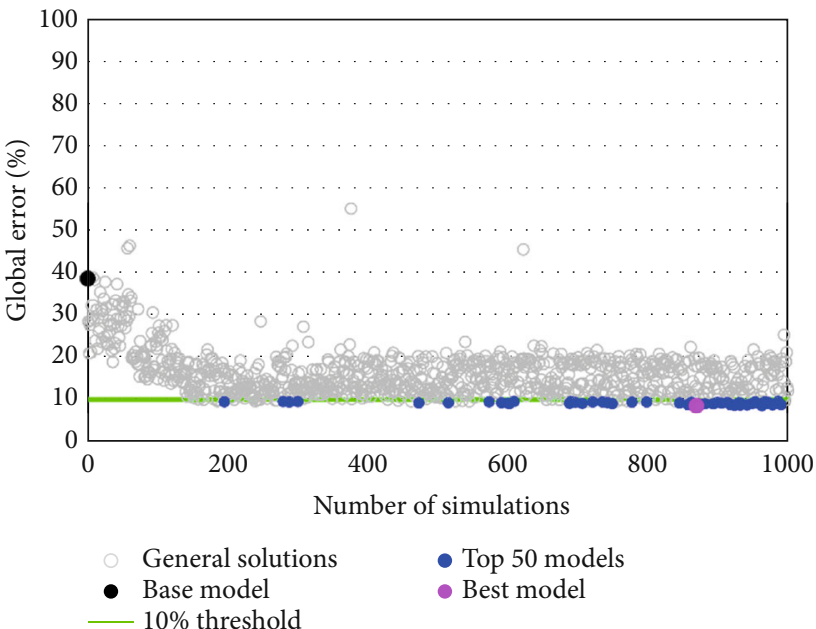

(d)

FIgURE 8: History matching results in terms of errors: (a) cumulative gas production, (b) cumulative water production, (c) bottom-hole pressure, and (d) the global error.

water production for both wells which are $1.5 \%$ and $6 \%$, respectively. However, we still see a relatively large error in $\mathrm{BHP}$ which is $17 \%$, and yet it at least captures the decreasing trends. It is worth noting that the gas and water production are from measurements, whereas BHP is what we backcalculated using production rates, PVT data, and well configuration which comes with uncertainty. Therefore, having measured BHP data from gauges in downhole would be greatly helpful to reduce such uncertainty.

Figure 10 shows distributions of uncertain parameters before and after the model calibration. Compared to the initial distribution, the parameters generally show sharper distributions after history matching implying that uncertainty associated with the parameters have reduced [26, 27]. It was found that the ranges of the calibrate parameters are $200-250 \mathrm{ft}$ for the fracture half length, 100-140 ft for the fracture height, and $0.7-0.75$ for the fracture water saturation. Fracture permeability for well A (10-30 md) shows higher value than well $\mathrm{B}(5-15 \mathrm{md})$. This is attributed to the production data of the wells (Figure 1) that well A outperformed well B, which is possibly caused by the depletion effect of the adjacent offset well, yet not accounted in the reservoir modeling. In other words, in order to reproduce the history data that well A produced more fluid than well $\mathrm{B}$, well $\mathrm{A}$ has to have a higher fracture permeability as a consequence. High water saturation along the fractures is also calibrated to demonstrate a high water cut in early time because of stimulation water.

As shown in the sensitivity analysis (Figure 7), parameters associated with hydraulic fractures and permeability enhanced zone have huge impact on the productions in unconventional reservoirs. The presented study only utilizes production history data and reservoir simulation to calibrate the hydraulic fracture parameters. However, integrating recently advanced measurements and techniques such as distributed acoustic sensor (DAS), distributed temperature sensor (DTS) $[17,28,29]$, and seismic wave information [30-32] would definitely help better understand geometry and properties of hydraulic fractures. 


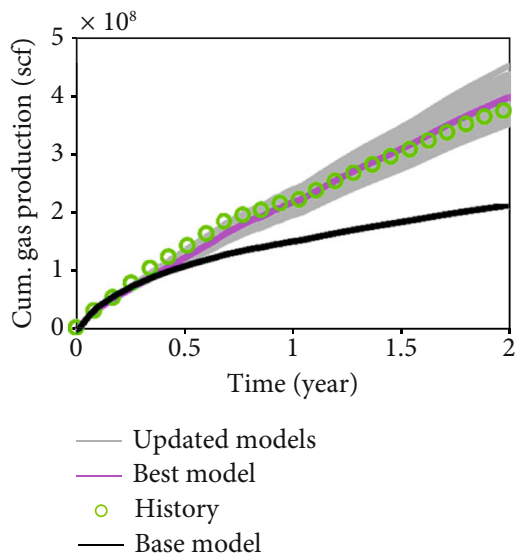

(a)

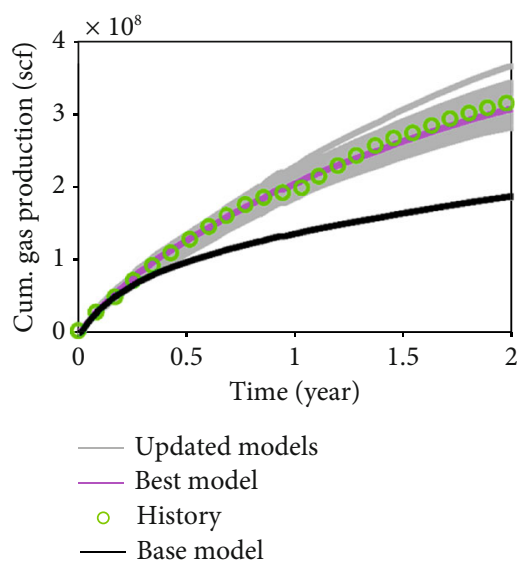

(d)

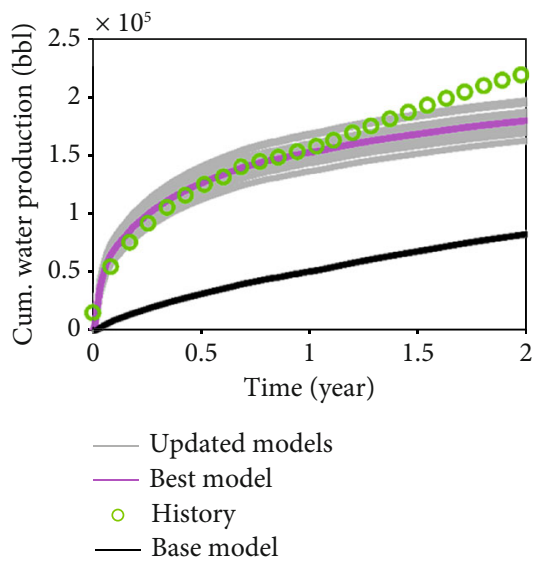

(b)

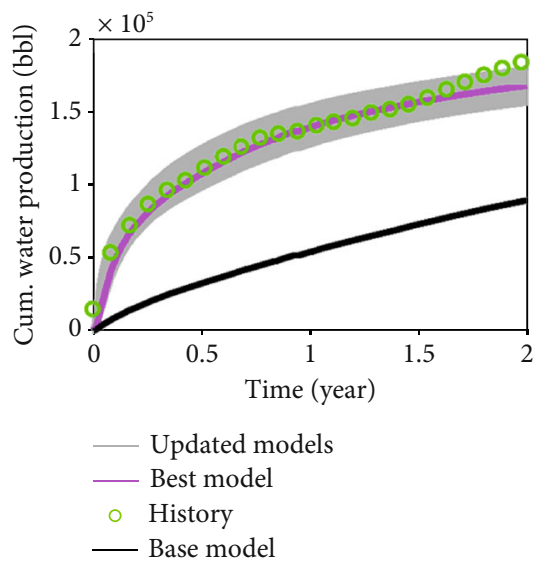

(e)
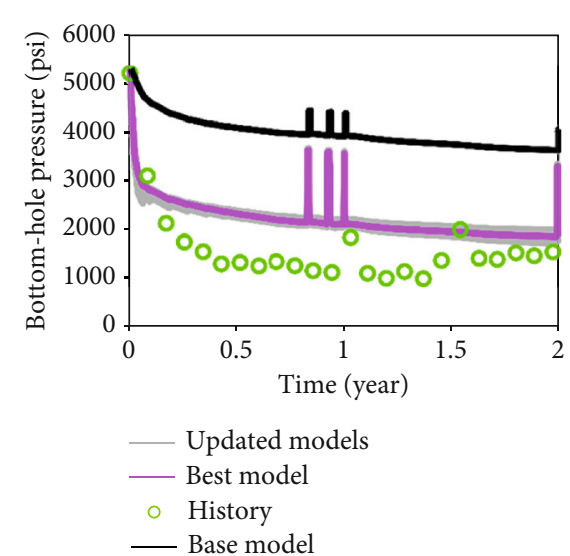

(c)

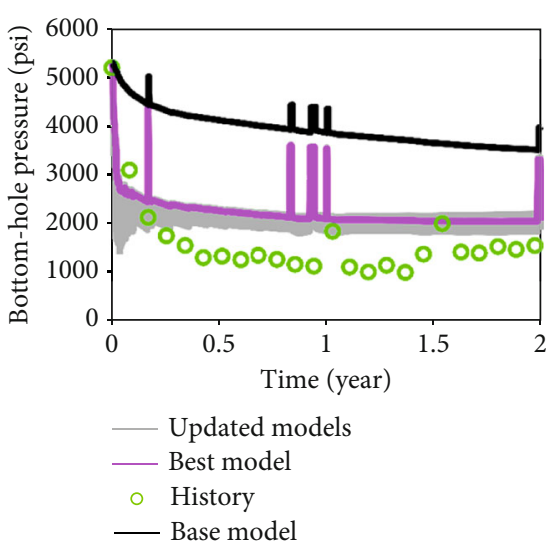

(f)

FIGURE 9: Two-year history matching simulation results: (a) cumulative gas production of well A, (b) cumulative water production of well A, (c) BHP of well A, (d) cumulative gas production of well B, (e) cumulative water production of well B, and (f) cumulative water production of well B.

We pick the best model to see how pressure has changed in the calibrated reservoir model with time. Figure 11 shows the depletion of the reservoir in the best model from 1 month to 12 months after the production with a 4 -month interval. It is observed that the majority of pressure depletion occurred in the first 4 months, and there is no significant difference after 4 months. Also, from the pressure depletion in early time, we can see the stimulated reservoir volume. The calibrated permeability enhanced zone has similar length to the main hydraulic fractures, possibly implying that the reservoir stimulation created a complex fracture network rather than planar fractures.

Figure 12 shows pressure profiles of the simulation model along the arrows in Figure 11(a), pointing $i$ and $k$-directions. Figure 12(a) shows the pressure profile in the $i$-direction with the $x$-axis being the distance in the $i$-coordinate, $y$-axis being the pressure drop (initial pressure-pressure at certain time), and red and cyan stars indicating locations of well A and well B, respectively. As previously observed in Figure 11, the pressure profiles in Figure 12(a) confirm that the reservoir is quickly depleted in the first 4 months, and the difference in the pressure drop diminishes afterward. The shapes of the pressure profile reveal that pressure depletion in the reservoir is dominated by hydraulic fractures and permeability enhanced zones. It is also observed that even before the first 4 months of production, concavities in the figure from the wells are connected, which implies that well interference occurs with the given reservoir stimulation and well configuration. Figure 12 (b) shows the pressure profile in the $k$ -direction at different times with a red star indicating the location of perforation. It is shown that the pressure front propagates $300 \mathrm{ft}$ upward and $100 \mathrm{ft}$ downward, and the local minimum reservoir pressure in the profiles reaches $40 \%$ of the initial reservoir pressure after 1 year of production. It is important to understand how the reservoir has been depleted especially when it comes to placing child wells. This is because depending on the degree of the reservoir depletion for the child well, the child well might experience a significant production degradation [33].

\section{Production Forecasting}

After history matching, top 50 well-matched models were selected for the production forecasting. The objective of the 


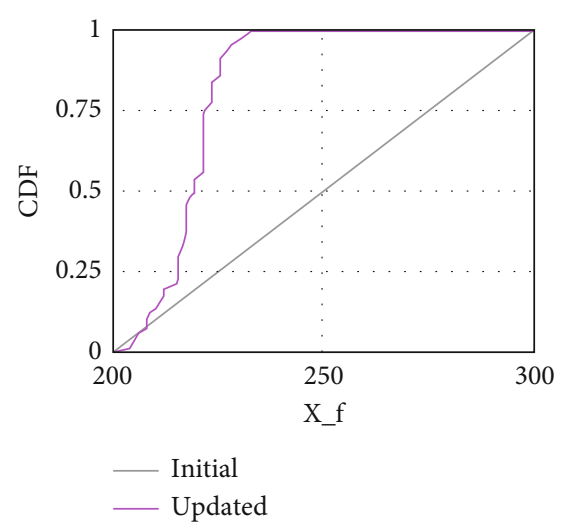

(a)

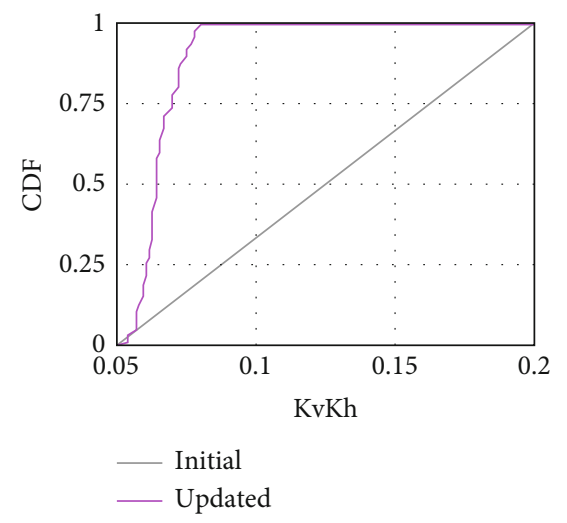

(d)

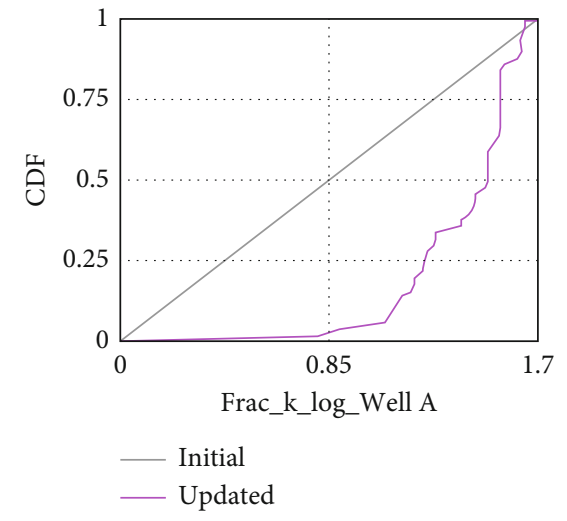

(b)

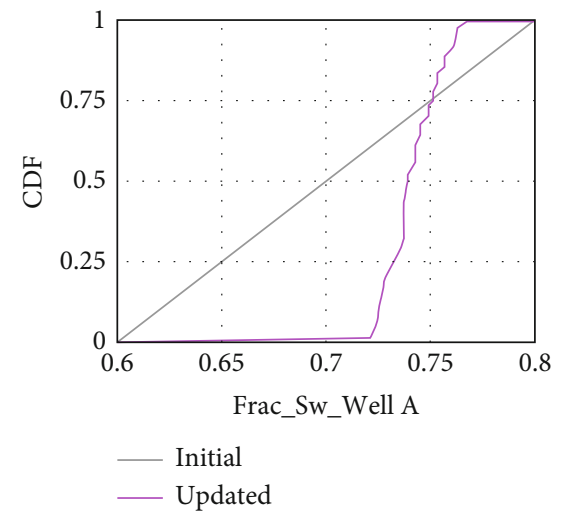

(e)

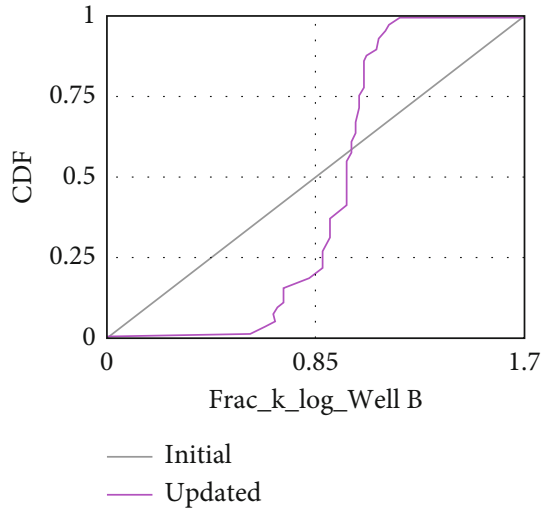

(c)

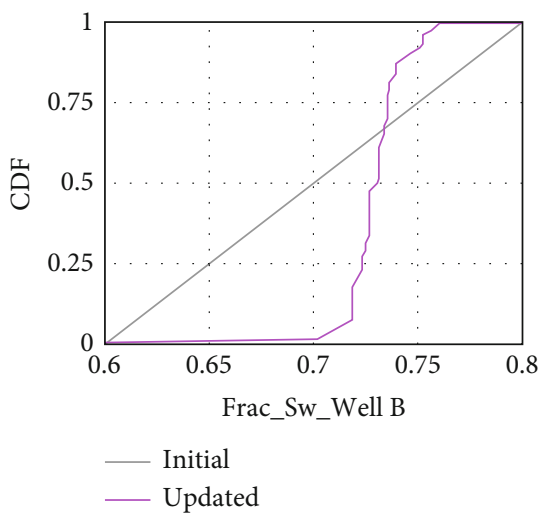

(f)

FIGURE 10: The cumulative distribution function of history matching parameters before/after history matching: (a) fracture half length, (b) fracture permeability for well A, (c) fracture permeability for well B, (d) permeability anisotropy, (e) fracture water saturation for well A, and (f) fracture water saturation for well B.

production forecasting is to evaluate EUR of two wells by simulating future production of the wells. During forecasting, the wells are constrained by fixed BHP for the total of 35 years. One of the advantages of taking such approach is that performance prediction comes with a range rather than one deterministic value, and this allows us to employ probabilistic analysis. Figure 13 shows a cumulative oil and gas production prediction of the two wells. In the figure, all of the models closely reproduce the history data within the history matching period. After the history, the top 50 models start to spread out widely, forming a range of predicted production, and the prediction by the best model is within the range.

Postprocessed forecasting results are illustrated with a histogram and cumulative distribution function in Figure 14 and summarized in Table 4. EUR for well $\mathrm{A}$ is distributed between $586-639 \mathrm{Mbbl}$ while well $\mathrm{B}$ has a range of $570-641 \mathrm{Mbbl}$. However, in terms of P50, well A (610MBO) shows a higher value than well B (605MBO). This is consistent with the previous production history which is possibly attributed to calibrated higher fracture permeability for well $A$. In reality, there might be some depletion effect from the offset well causing well B performing slightly lower, yet it is not accounted in the reservoir model.
We also investigated how reservoir is going to be depleted especially in the near future which mainly concerns with child wells. Better understanding of reservoir depletion helps us to seek potential benefits of the asset, and it is ultimately advantageous for development planning. Figure 15(a) shows the difference in reservoir pressure in the 3D reservoir model, and a part of the model is removed to reveal pressure change inside. We can see that the depletion is significant primarily in the stimulated region of the reservoir. Figure 15(b) shows the pressure difference in the $i-k$ cross-section $(j=237)$. The bottom layers of the reservoir barely experience pressure change because of the low permeability of the formation while upper layers show a pressure drop. The magenta star in Figure 15(b) illustrates a hypothetical future well. The area is already depleted, around 1,400 psi pressure difference. However, additional simulation modeling work should be required to investigate whether placing a new well at this location will be adversely affected because of pressure depletion from the parent wells. Another observation is that production is not solely attributed to the stimulated area but also part of the reservoir that is not stimulated at all. This means that efficiently stimulating reservoir is absolutely critical but having the "good rock" in the first place is also important in the hydrocarbon recovery even in tight shale reservoirs. 


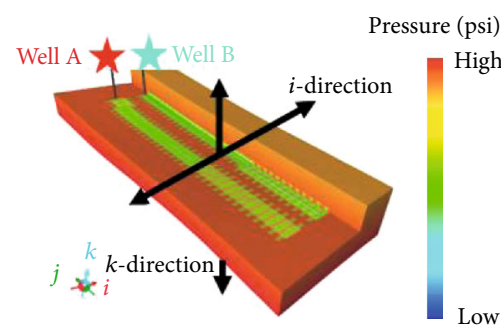

(a)

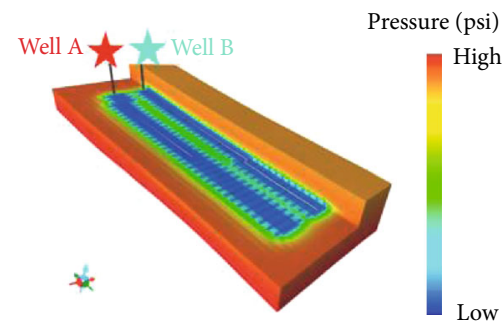

(c)

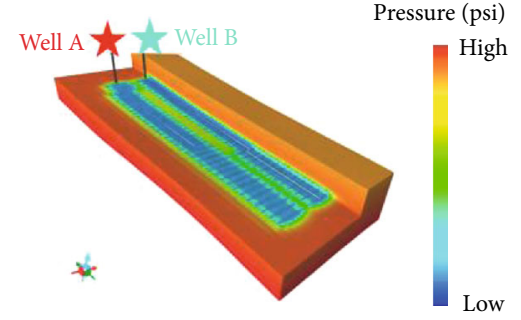

(b)

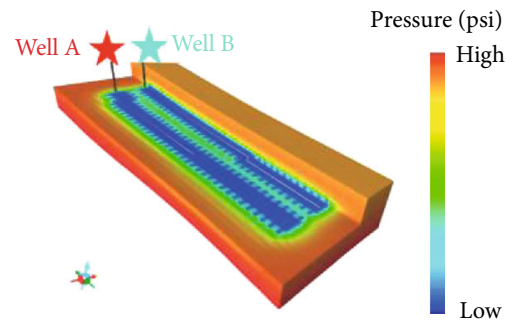

(d)

FiguRE 11: Reservoir depletion at different times: production after (a) 1 month, (b) 4 months, (c) 8 months, and (d) 12 months.

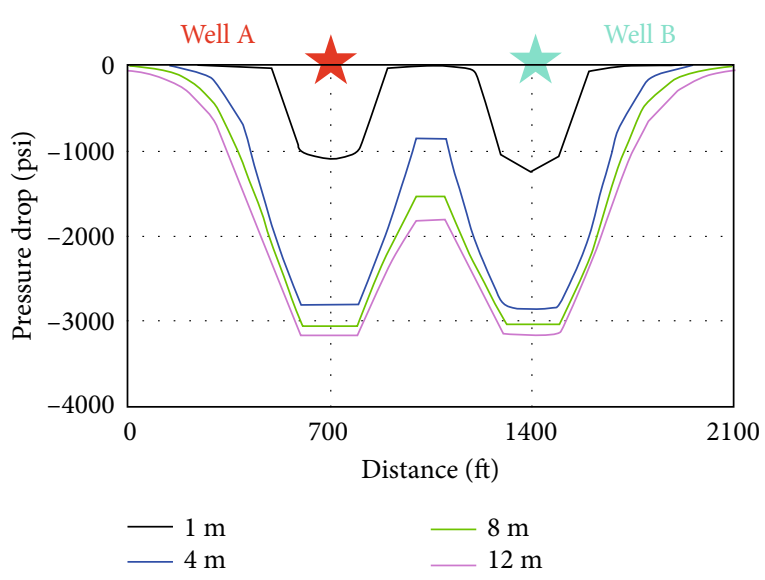

(a)

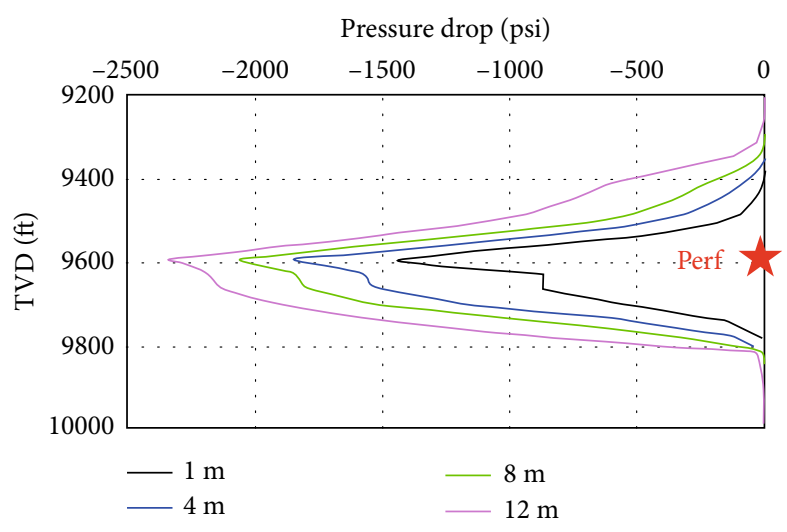

(b)

FIGURE 12: Reservoir pressure profiles at different times: (a) pressure profile in the $i$-direction and (b) the $k$-direction from 1 month to 12 months.

\section{Lateral Spacing Sensitivity}

Given the best model, we conducted the sensitivity study for lateral well spacing to find the maximum volume recovery and economic benefits in the target area. The only variable in the sensitivity study is well spacing, and other parameters such as fracture geometry and properties which can have an impact on the results are all fixed. The well constraint is fixed BHP for the total of 35 years, the same as the previous production forecasting, to see the impact of lateral well spacing on EUR. The emphasis should be put on how the simulation model is shaped and how the produced volume and net present value (NPV) are examined per one section for this spacing sensitivity study. As shown in Figure 16, we set the boundary of the reservoir to vary as the well spacing changes.
For example, in the case of $660 \mathrm{ft}$ spacing case (Figure 16(a)), the gap between the wells and the boundary of the reservoir model in the $i$-direction is the half of the well spacing, $330 \mathrm{ft}$, in both sides that the total length of the entire subsection is $1,320 \mathrm{ft}$. Similarly, in the case of $1,320 \mathrm{ft}$ well spacing, $660 \mathrm{ft}$ gap places in both sides of the reservoir model that the length of the entire subsection is a double of the well spacing, 2,640 ft (Figure 16(b)).

To examine the produced oil volume and NPV per one section, the volume and accordingly calculated NPV from the two-well pad model are simply weighted. Figure 16(c) shows weights with respect to well spacing in a simulation model. The weight of a $660 \mathrm{ft}$ well spacing in a model yields to 4 and that of $1,320 \mathrm{ft}$ well spacing is 2 . This is because four $660 \mathrm{ft}$ well spacing models can be fit in one section 


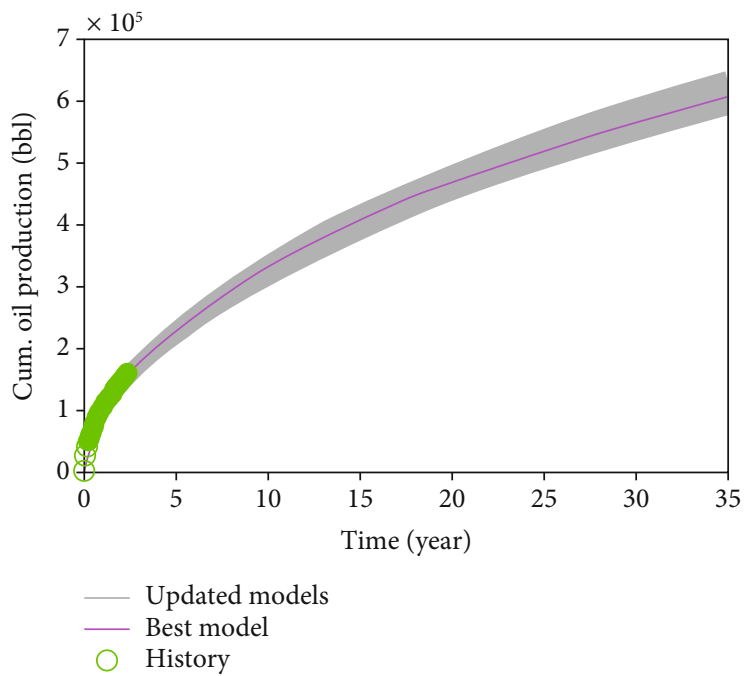

(a)

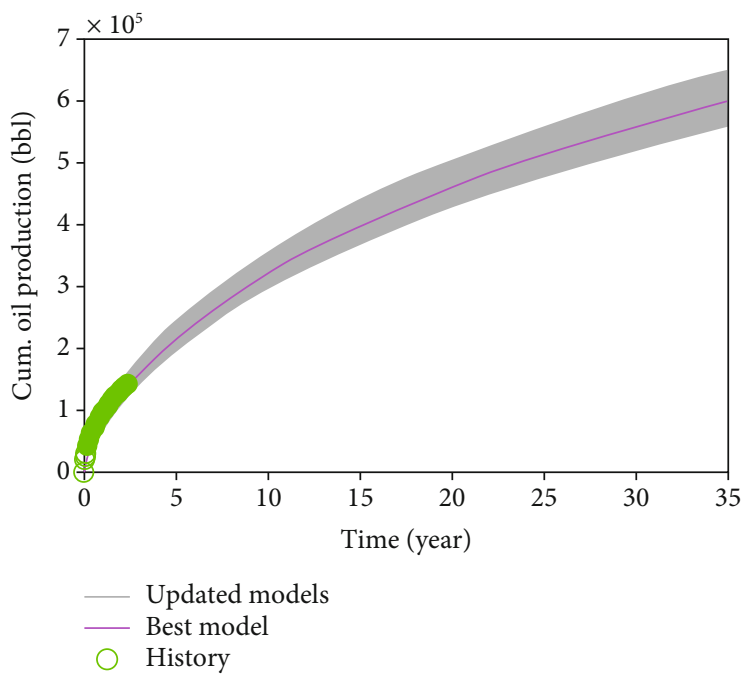

(c)

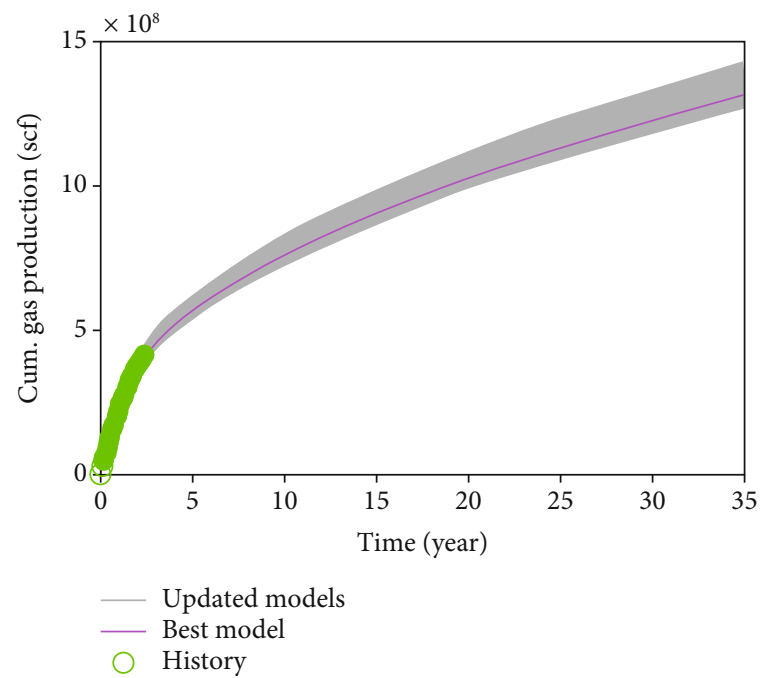

(b)

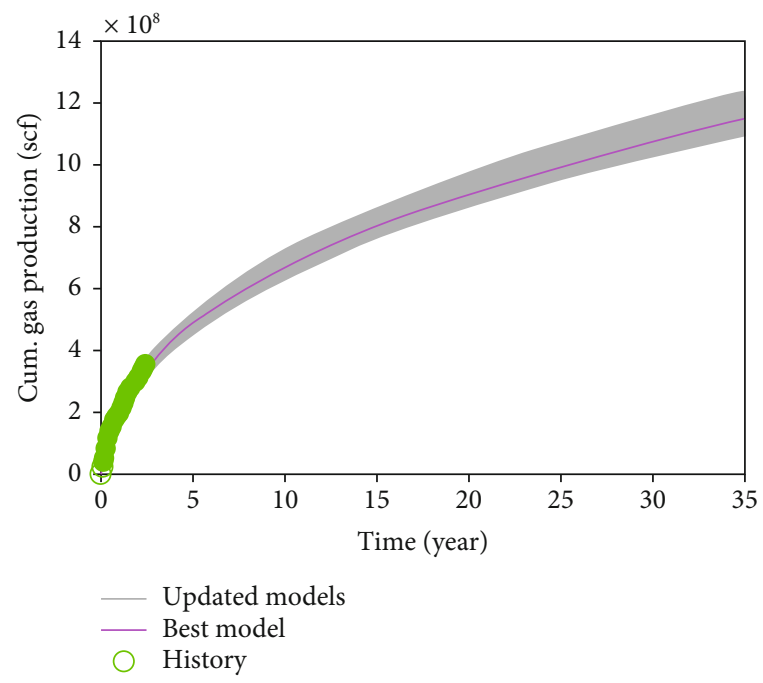

(d)

FIGURE 13: Cumulative oil and gas production forecasting of top 50 history-matched models: (a) cumulative oil production for well A, (b) cumulative gas production for well A, (c) cumulative oil production for well B, and (d) cumulative gas production for well B.

$(5,260 \mathrm{ft} \times 5,260 \mathrm{ft})$ and so can two of the $1,320 \mathrm{ft}$ well spacing models. The concept of the weight in the study is fairly similar with well per section (WPS) $[8,34]$ except that our case is based on two-well pad. Therefore, the weight for this study is simply the half of the WPS in the previous study.

For the lateral spacing sensitivity study, several key assumptions are made.

(i) A two-well pad model forms a symmetry when it extends to one section that no-flow boundary condition is imposed between two-well pad models. This allows us to only simulate a part of one section to evaluate the entire section

(ii) Change in well spacing might result in different fracture geometries and conductivities because of the stress shadow effect and connection with natural fractures $[9,19]$. However, we assume that fracture geometry and conductivity are the same as the history-matched model which is originally $660 \mathrm{ft}$ well spacing

(iii) All of the wells in the section are assumed to be completed and start producing at the same time for the NPV calculation. This justifies the simple multiplication yet might not be always the case of a field development in reality

NPV calculation is based on actual capital expenditure (CAPEX), lease operating expenses (LOE), working interest (WI), and net revenue interest (NRI) of the asset. Economic assumptions for the calculation include flat $120 \mathrm{bbl} / \mathrm{MMscf}$ of NGL yield, flat commodity price, and $10 \%$ of the discount rate (Table 5). 


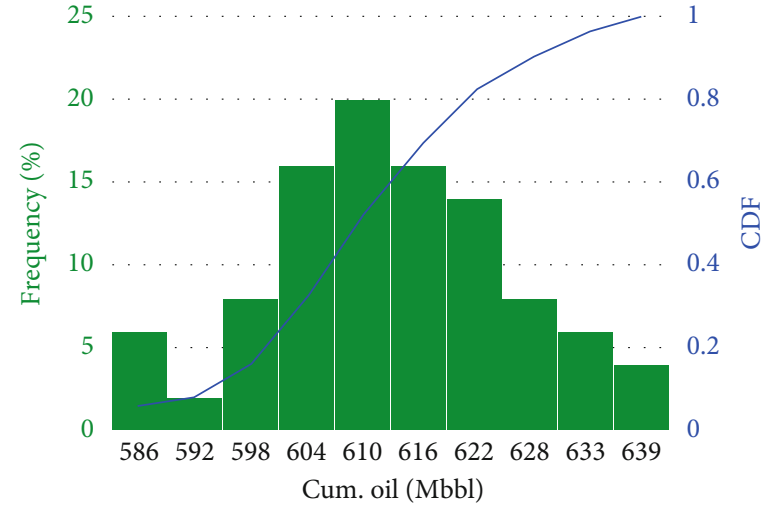

(a)

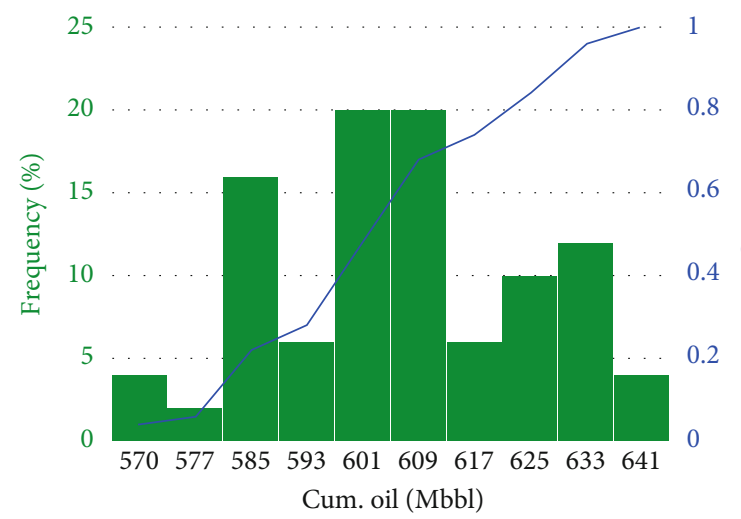

(c)

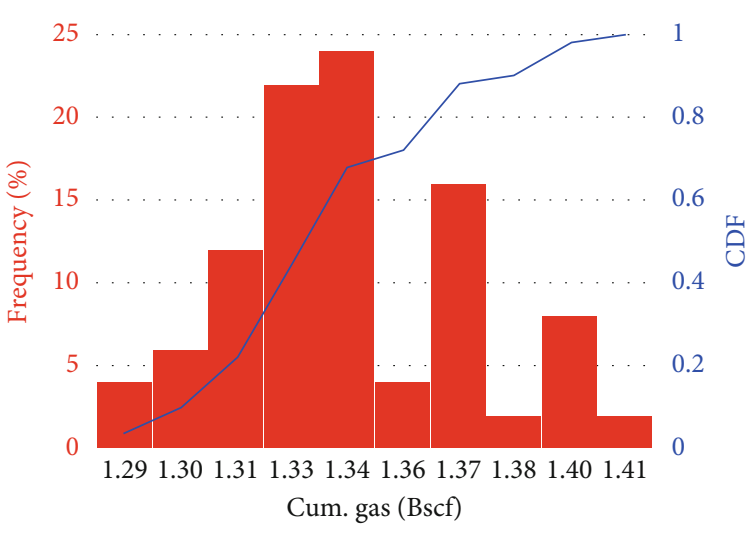

(b)

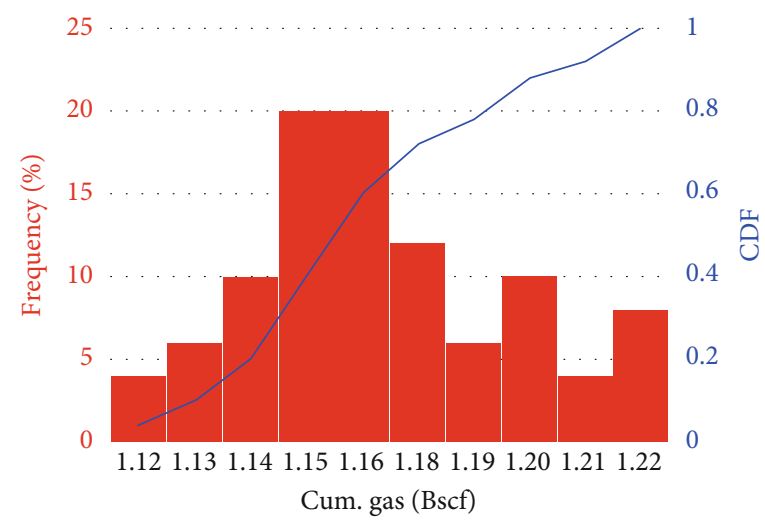

(d)

FIGURE 14: Histogram and cumulative distribution function of forecasting results: (a) well A oil production forecast, (b) well A gas production forecast, (c) well B oil production forecast, and (d) well B gas production forecast.

TABle 4: P10, P50, and P90 of the production forecast for the wells and comparison with DCA prediction.

\begin{tabular}{lcccc}
\hline & \multicolumn{2}{c}{ Well A } & \multicolumn{2}{c}{ Well B } \\
& Oil (Mbbl) & Gas (Bscf) & Oil (Mbbl) & Gas (Bscf) \\
\hline P10 & 628 & 1.38 & 629 & 1.21 \\
P50 & 610 & 1.34 & 605 & 1.16 \\
P90 & 598 & 1.30 & 580 & 1.13 \\
DCA prediction & 459 & 1.55 & 415 & 1.15 \\
\hline
\end{tabular}

Figure 17 shows the well spacing sensitivity on oil EUR and NPV10 per two-well pad and per section with a magenta star indicating the current well spacing practice. It is shown that oil recovery and NPV increase with a larger well spacing in well pad. This is because wells with larger spacing drain more reservoir volume, experiencing less interference with each other. Therefore, the well pad with larger well spacing leads to better economic metrics. However, when it comes to oil EUR per section, tighter spacing provides a higher oil recovery while there is no increase in the EUR with the spacing tighter than the current practice. Given the current completion design, this deduces two points: (1) development of the section with well spacing larger than the current practice leaves unexploited oil behind, and (2) the well spacing tighter than the current practice is not optimum. Therefore, it is recommended to maintain or widen the distance between wells to maximize recovery in the section, given the current completion design. Such a trend is also observed in previous studies [8, 35-37] that EUR augments as WPS increases and after a threshold, EUR no longer increases. As discussed in Zhu, Forrest [8] and Pankaj, and Shukla [38], the threshold is believed to highly depend on the uncovered region between stimulated wells mainly concerning with fracture half length. Moreover, initial rock quality, which also contributes to the production, should impact the threshold.

Using NPV as economic metrics, the reservoir model suggests a more conservative approach for a sectional development scenario. It suggests that the well spacing needs to be increased between $40-50 \%$ from the current practice. In this case, additional $15-20 \%$ monetary value is expected to be realized. This is because tighter spacing requires more wells to be drilled and completed which adds cost to develop the entire section. Given economic assumptions, smaller WPS is still economically beneficial than the current practice because to spend less expenditure is as important as to earn more revenue from the commodity. This tells us that the volume-wise optimum well spacing is not necessarily identical to the economic-wise optimum well spacing in one section development. 


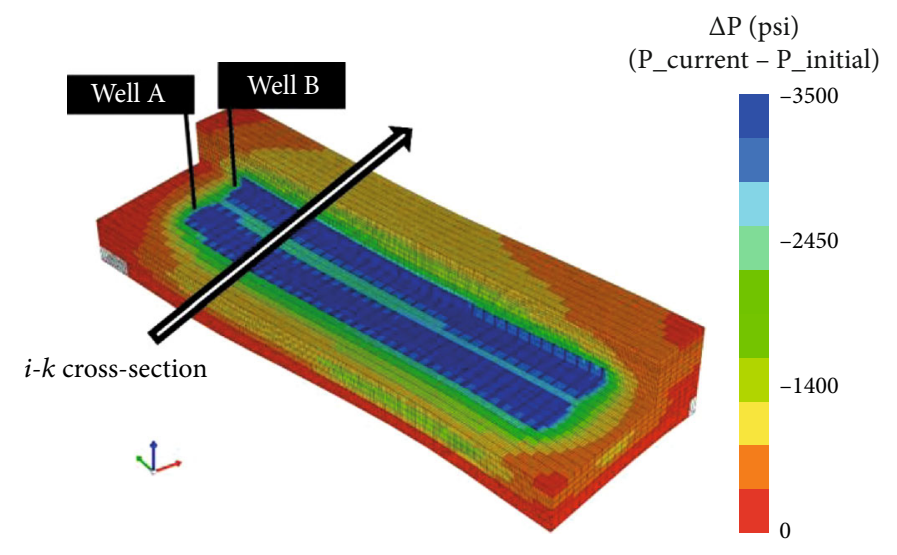

(a)

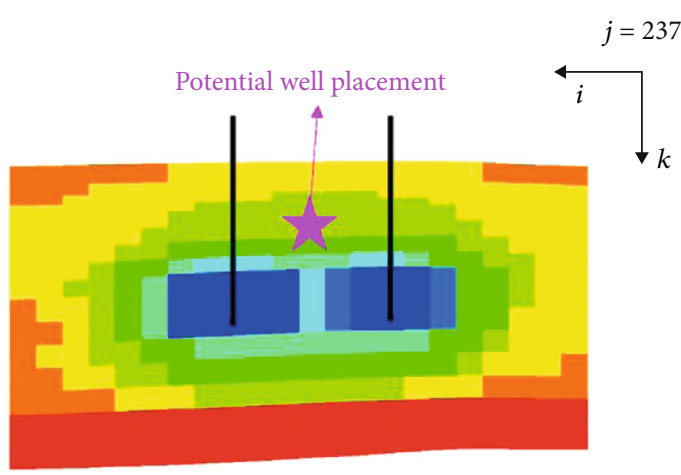

(b)

FIGURE 15: Pressure change of the history-matched model after 1 year: (a) 3D model view and (b) $i$ - $k$ cross-section view.

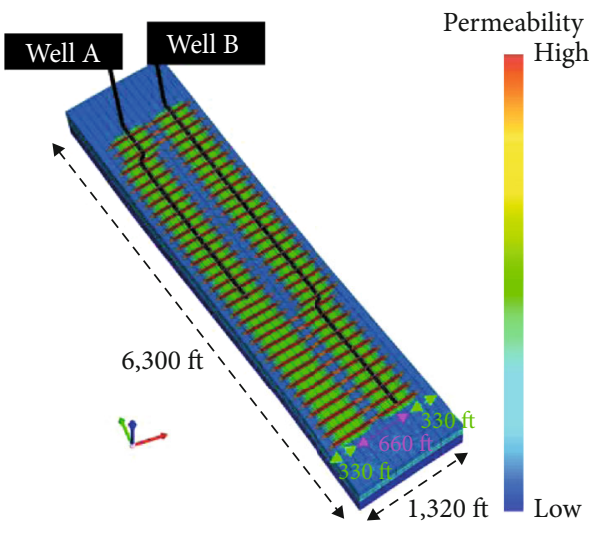

(a)

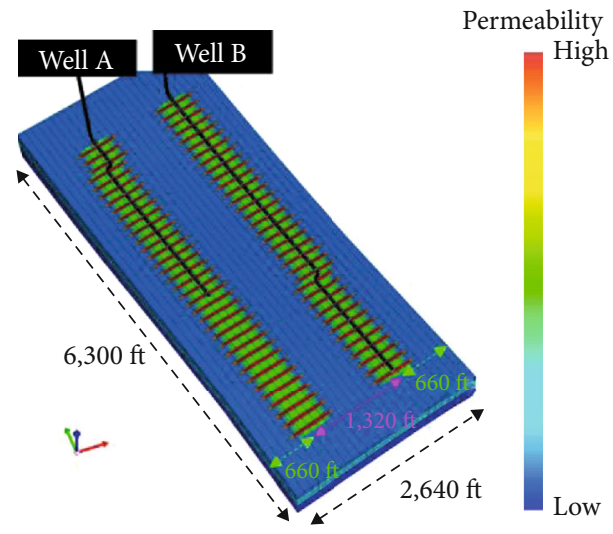

(b)

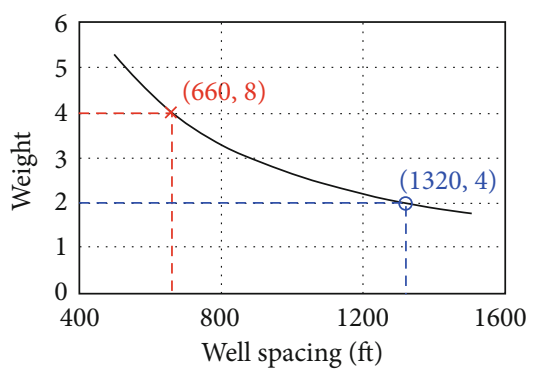

(c)

FIGURE 16: Reservoir models for lateral spacing sensitivity and weight: (a) $660 \mathrm{ft}$ spacing, (b) 1,320 ft spacing, and (c) corresponding weights for production estimation.

TABle 5: Economic assumptions for the NPV10 calculation.

\begin{tabular}{lccc}
\hline CAPEX/1-mile well & LOE & Pricing (flat) & WI/NRI \\
\hline \multirow{3}{*}{ \$6.75MM } & Parsley 17 & Oil: $\$ 50 / \mathrm{bbl}$ & \\
& HZ LOE & Gas $/ \mathrm{mscf}$ & $96.1 \% / 72.3 \%$ \\
& & NGL: $\$ 20 / \mathrm{bbl}$ & \\
\hline
\end{tabular}

While some of the factors in the NPV calculation like CAPEX, LOE, WI, and NRI do not change much in life of a well, the commodity price can be relatively volatile. There- fore, the economic-wise optimum well spacing can change. For example, Figure 18 shows NPV10 per section at different commodity prices. The higher commodity price drives the economically optimum well spacing tighter while larger spacing is economically favorable in low commodity price environment. However, even though the commodity price is extremely high, the optimum well spacing for the one section in the area will not be tighter than the current practice. As discussed in Figure 17, spacing tighter than the current practice do not take benefit in the oil recovery volume anymore with the given completion design. 


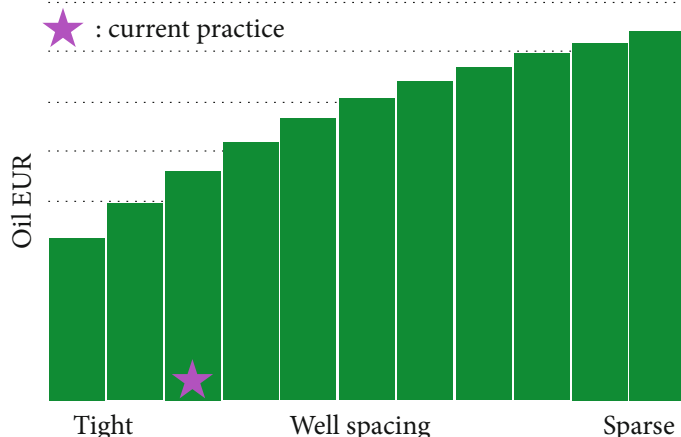

(a)

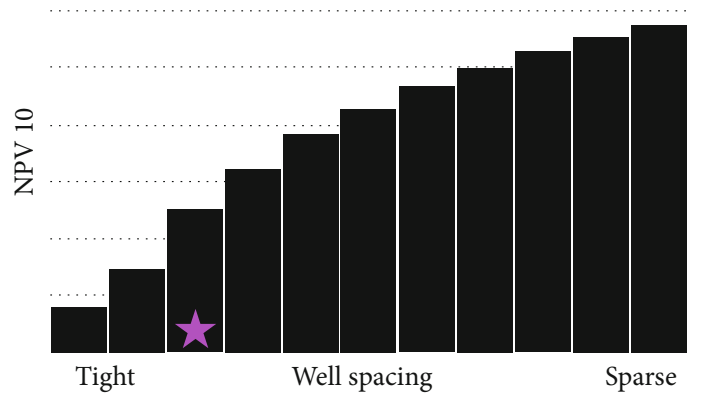

(c)

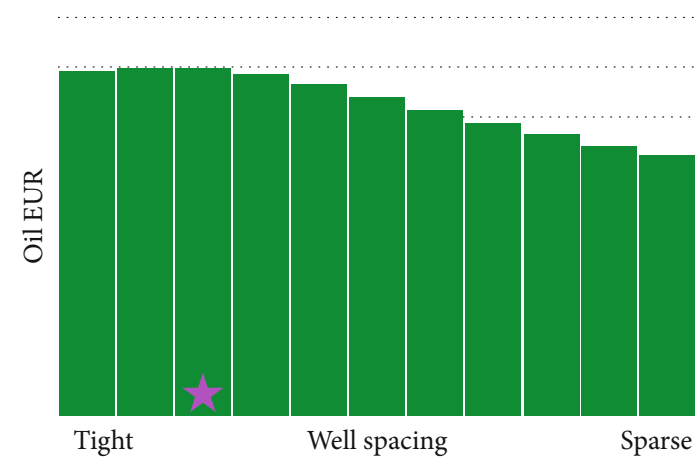

(b)

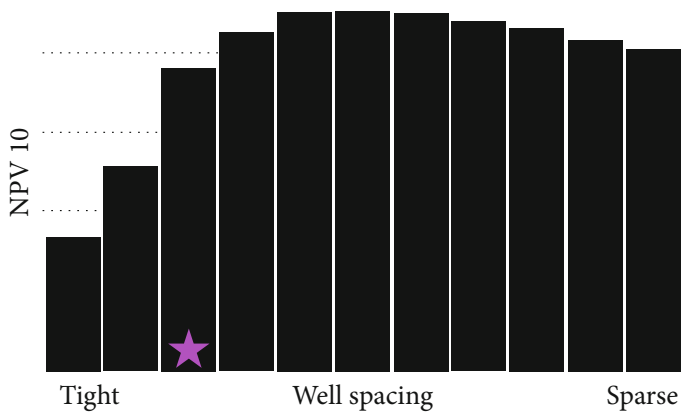

(d)

FIGURE 17: Lateral well spacing sensitivity results: (a) EUR per well pad, (b) EUR per one section, (c) NPV10 per well pad, and (d) NPV10 per one section.

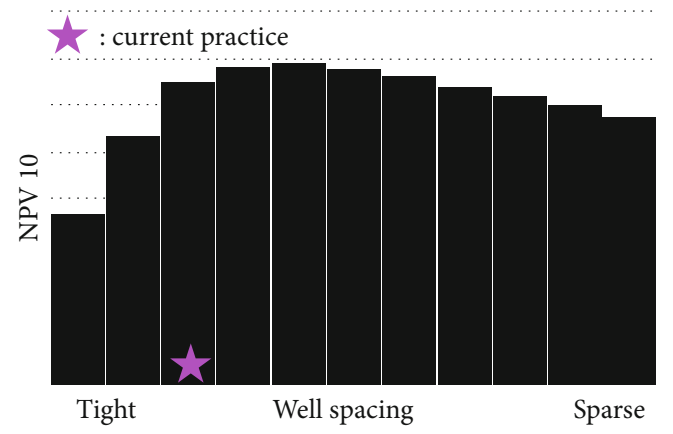

(a)

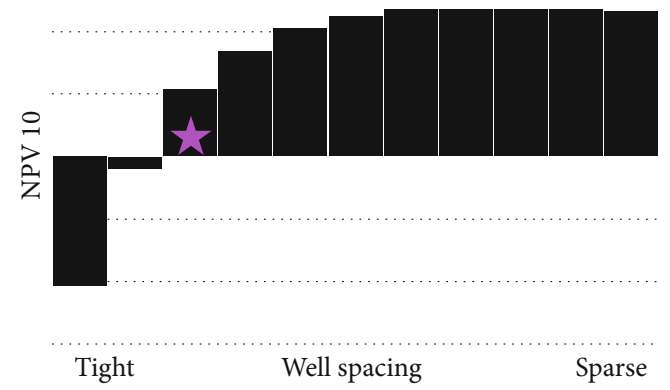

(b)

FIGURE 18: NPV10 per section at different commodity prices: (a) commodity price $20 \%$ higher than the assumption and (b) commodity price $20 \%$ lower than the assumption.

\section{Conclusion}

Finding the optimum well spacing is a key factor for the successful unconventional field development. However, to investigate the optimum well spacing is not straightforward because of complex dynamics in unconventional reservoirs, including hydraulic fracture property and geometry and well interference. In order to adequately account for such complexity, we performed the flow simulation-based reservoir modeling to find the optimum well spacing in the Midland Basin in terms of oil volume and economic metrics.

We first history-matched the two-well pad with less than $10 \%$ of global error which is the sum of errors in cumulative gas and water production and BHP. The calibrated fracture geometry, half length, and height were found to be within reasonable ranges based on the offset response and analytical solution. Production forecast results based on the top 50 history-matched models showed that P50 of oil EUR for the wells was within an acceptable range compared to deterministic EUR estimates. With the history-matched model, lateral well spacing sensitivity was investigated. It was found that the well spacing tighter than the current development practice can potentially yield suboptimal areal recovery. Furthermore, the economic evaluation has provided an indication that the additional monetary value can be realized when the well spacing is widened, up to $150 \%$ of the current 
field assumption. Even though this study targets a specific field site, the presented workflow and method to investigate reservoir depletion, stimulation characterization, and well spacing optimization for multiwell pad should be readily applicable to other acreage positions.

\section{Data Availability}

Data are available from the authors upon reasonable request and with permission of the operator.

\section{Disclosure}

The paper was presented in Unconventional Resources Technology Conference.

\section{Conflicts of Interest}

The authors declare that they have no conflicts of interest.

\section{Acknowledgments}

The authors would like to thank the lead editor and the anonymous reviewers for their constructive comments throughout the peer-review process. The paper was presented in Unconventional Resources Technology Conference and the authors thank Parsley Energy for allowing the authors to publish this paper. The open access publishing fees for this article have been covered by the Texas A\&M University Open Access to Knowledge Fund (OAKFund), supported by the University Libraries and the authors appreciate their support.

\section{References}

[1] EIA, Permian Basin Wolfcamp Shale Play Geology review, 2018.

[2] EIA, U.S. Crude oil and natural gas proved reserves, year-end 2016, U.S. Energy Information Publication report, 2017, https://www.ourenergypolicy.org/wp-content/uploads/2018/ 02/U.S.-Crude-Oil-and-Natural-Gas-Proved-Reserves.pdf.

[3] S. B. Gaswirth, K. R. Marra, P. G. Lillis et al., Assessment of undiscovered continuous oil resources in the Wolfcamp shale of the Midland Basin, Permian Basin province, Texas, 2016, 2016.

[4] C. L. Cipolla, "Modeling production and evaluating fracture performance in unconventional gas reservoirs," Journal of Petroleum Technology, vol. 61, no. 9, pp. 84-90, 2013.

[5] A. S. Cullick, M. Carrillo, C. Clayton, and I. Ceyhan, "Wellspacing study to develop stacked tight oil pay in Midland Basin," in SPE Unconventional Resources Conference, vol. 14, Society of Petroleum Engineers, The Woodlands, Texas, USA, 2014.

[6] J. Pettegrew, J. Qiu, and L. Zhan, "Understanding Wolfcamp well performance - a workflow to describe the relationship between well spacing and EUR," in SPE/AAPG/SEG Unconventional Resources Technology Conference, p. 11, Unconventional Resources Technology Conference, San Antonio, Texas, USA, 2016.

[7] B. Liang, M. Du, and P. P. Yanez, "Subsurface well spacing optimization in the Permian Basin," in SPE/AAPG/SEG
Unconventional Resources Technology Conference, p. 12, Unconventional Resources Technology Conference, Austin, Texas, USA, 2017.

[8] J. Zhu, J. Forrest, H. Xiong, and A. Kianinejad, "Cluster spacing and well spacing optimization using multi-well simulation for the Lower Spraberry shale in Midland Basin," in SPE Liquids-Rich Basins Conference-North America, p. 14, Society of Petroleum Engineers, Midland, Texas, USA, 2017.

[9] F. Ajisafe, I. Solovyeva, A. Morales, E. Ejofodomi, and M. M. Porcu, "Impact of well spacing and interference on production performance in unconventional reservoirs, Permian Basin," in SPE/AAPG/SEG Unconventional Resources Technology Conference, p. 16, Unconventional Resources Technology Conference, Austin, Texas, USA, 2017.

[10] P. Pankaj, "Characterizing well spacing, well stacking, and well completion optimization in the Permian Basin: an improved and efficient workflow using cloud-based computing," in SPE/AAPG/SEG Unconventional Resources Technology Conference, p. 29, Unconventional Resources Technology Conference, Houston, Texas, USA, 2018.

[11] N. Bansal, J. Han, Y. Shin, and T. Blasingame, "Reservoir characterization to understand optimal well spacing - a Wolfcamp case study," in SPE/AAPG/SEG Unconventional Resources Technology Conference, p. 17, Unconventional Resources Technology Conference, Houston, Texas, USA, 2018.

[12] A. R. Hagedorn and K. E. Brown, "Experimental study of pressure gradients occurring during continuous two-phase flow in small-diameter vertical conduits," Journal of Petroleum Technology, vol. 17, no. 4, pp. 475-484, 2013.

[13] M. J. Economides, A. D. Hill, C. Ehlig-Economides, and D. Zhu, Petroleum production systems, Pearson Education, Boston, 2013.

[14] CMG, Computer Modeling Group Ltd, "Three-phase, blackoil reservoir Simulator," CMG IMEX User Guide, 2016.

[15] D. Cakici, C. Dick, A. Mookerjee, and B. Stephenson, "Marcellus well spacing optimization-pilot data integration and dynamic modeling study," in SPE/AAPG/SEG Unconventional Resources Technology Conference, p. 10, Unconventional Resources Technology Conference, Denver, Colorado, USA, 2013.

[16] J. Miskimins, R. Barree, B. E. Wheaton, D. Wood, and T. Lowe, "Integration of distributed temperature and distributed acoustic survey results with hydraulic fracture modeling: a case study in the Woodford shale," in SPE/AAPG/SEG Unconventional Resources Technology Conference, p. 14, Unconventional Resources Technology Conference, Denver, Colorado, USA, 2014.

[17] C. Ugueto, A. Gustavo, P. T. Huckabee, M. M. Molenaar, B. Wyker, and K. Somanchi, "Perforation cluster efficiency of cemented plug and perf limited entry completions; insights from fiber optics diagnostics," in SPE Hydraulic Fracturing Technology Conference, p. 17, Society of Petroleum Engineers, The Woodlands, Texas, USA, 2016.

[18] B. Wheaton, K. Haustveit, W. Deeg, J. Miskimins, and R. Barree, "A case study of completion effectiveness in the Eagle Ford Shale using DAS/DTS observations and hydraulic fracture modeling," in SPE Hydraulic Fracturing Technology Conference, p. 11, Society of Petroleum Engineers, The Woodlands, Texas, USA, 2016.

[19] N. B. Nagel, F. Zhang, M. A. Sanchez-Nagel, and B. Lee, "Evaluation of stress changes due to multi-stage hydraulic fracturing-consideration of field results," in ISRM International 
Symposium-EUROCK 2013, p. 6, International Society for Rock Mechanics and Rock Engineering, Wroclaw, Poland, 2013.

[20] J. Huang, C. Yang, X. Xue, and A. Datta-Gupta, "Simulation of coupled fracture propagation and well performance under different refracturing designs in shale reservoirs," in SPE Low Perm Symposium, p. 26, Society of Petroleum Engineers, Denver, Colorado, USA, 2016.

[21] K. Wu, J. Olson, M. T. Balhoff, and W. Yu, "Numerical analysis for promoting uniform development of simultaneous multiple-fracture propagation in horizontal wells," SPE Production \& Operations, vol. 32, no. 1, pp. 41-50, 2017.

[22] M. Mirzaei and C. L. Cipolla, "A workflow for modeling and simulation of hydraulic fractures in unconventional gas reservoirs," in SPE Middle East Unconventional Gas Conference and Exhibition, p. 11, Society of Petroleum Engineers, Abu Dhabi, UAE, 2012.

[23] A. Iino, A. Vyas, J. Huang et al., "Efficient modeling and history matching of shale oil reservoirs using the fast marching method: field application and validation," in SPE Western Regional Meeting, Society of Petroleum Engineers, Bakersfield, California, 2017.

[24] CMG, Computer Modelling Group Ltd, "Enhance \& Accelerate Sensitivity Analysis, History Matching, Optimization \& Uncertainty Analysis," CMG CMOST User Guide, 2016.

[25] C. E. Espinoza, "A new formulation for numerical simulation of compaction, sensitivity studies for steam injection," in SPE Reservoir Simulation Symposium, Society of Petroleum Engineers, San Francisco, California, 1983.

[26] H. Kim and A. Datta-Gupta, "Multiresolution grid connectivitybased transform for efficient history matching of unconventional reservoirs," SPE Journal, vol. 25, no. 4, pp. 1895-1915, 2020.

[27] J. Park, A. Iino, A. Datta-Gupta, J. Bi, and S. Sankaran, "Novel hybrid fast marching method-based simulation workflow for rapid history matching and completion design optimization of hydraulically fractured shale wells," Journal of Petroleum Science and Engineering, vol. 196, article 107718, 2020.

[28] S. Zhang, H. Tang, R. Hurt, V. Jayaram, and J. Wagner, "Joint interpretation of fiber optics and downhole gauge data for near wellbore region characterization," in SPE Hydraulic Fracturing Technology Conference and Exhibition, Society of Petroleum Engineers, 2020.

[29] S. Zhang and D. Zhu, "Inversion of Downhole temperature measurements in multistage-fracturing stimulation of horizontal wells in unconventional reservoirs," SPE Production \& Operations, vol. 35, no. 2, pp. 231-244, 2020.

[30] E. Sotelo, Y. Cho, and R. L. Gibson Jr., "Compliance estimation and multiscale seismic simulation of hydraulic fractures," Interpretation, vol. 6, no. 4, pp. T951-T965, 2018.

[31] Y. Cho, R. L. Gibson Jr., M. Vasilyeva, and Y. Efendiev, “Generalized multiscale finite elements for simulation of elasticwave propagation in fractured media," Geophysics, vol. 83, no. 1, pp. WA9-WA20, 2018.

[32] Y. Cho, R. L. Gibson Jr., J. Lee, and C. Shin, "Linear-slip discrete fracture network model and multiscale seismic wave simulation," Journal of Applied Geophysics, vol. 164, pp. 140$152,2019$.

[33] J. Park, A. Datta-Gupta, A. Singh, and S. Sankaran, "Hybrid physics and data-driven modeling for unconventional field development-onshore US Basin Case Study," Unconventional Resources Technology Conference (URTEC), 2020.

[34] R. Cao, R. Li, A. Girardi, N. Chowdhury, and C. Chen, "Well interference and optimum well spacing for Wolfcamp development at Permian Basin," in SPE/AAPG/SEG Unconventional Resources Technology Conference, Unconventional Resources Technology Conference, Austin, Texas, USA, 2017.

[35] V. Sahai, G. Jackson, R. R. Rai, and L. Coble, "Optimal well spacing configurations for unconventional gas reservoirs," in SPE Americas Unconventional Resources Conference, Society of Petroleum Engineers, Pittsburgh, Pennsylvania USA, 2012.

[36] F. Lalehrokh and J. Bouma, "Well spacing optimization in Eagle Ford," in SPE/CSUR Unconventional Resources Conference-Canada, Society of Petroleum Engineers, Calgary, Alberta, Canada, 2014.

[37] J. Zhu, J. Forrest, H. Xiong, and Y. Pradhan, "Lessons learned from existing horizontal fractured wells on university lands in the Midland Basin: rate transient analyses vs completion and field development optimization," in SPE/AAPG/SEG Unconventional Resources Technology Conference, Unconventional Resources Technology Conference, Houston, Texas, USA, 2018.

[38] P. Pankaj, P. Shukla, P. Kavousi, and T. Carr, "Hydraulic fracture and reservoir characterization for determining optimal well spacing in the Marcellus Shale," in SPE Liquids-Rich Basins Conference-North America, Society of Petroleum Engineers, Midland, Texas, USA, 2018. 